\title{
Heart Rate Variability, Standard of Measurement, Physiological Interpretation and Clinical Use in Mountain Marathon Runners during Sleep and after Acclimatization at $3480 \mathrm{~m}$
}

\author{
Ivana Gritti ${ }^{*}$, Stefano Defendi ${ }^{1}$, Clara Mauri ${ }^{1}$, Giuseppe Banfi ${ }^{1}$, \\ Piergiorgio Duca ${ }^{1}$, Giulio Sergio Roi ${ }^{2}$ \\ ${ }^{1}$ Department of Biomedical and Clinical Science Luigi Sacco, University of Milan, Milan, Italy \\ ${ }^{2}$ Education and Research Department Isokinetic, Bologna, Italy \\ Email: *Ivana.Gritti@unimi.it, Piergiorgio.Duca@unimi.it, gs.roi@isokinetic.com
}

Received November 19, 2012; revised December 20, 2012; accepted December 27, 2012

\begin{abstract}
Fluctuations in autonomic cardiovascular regulation during exposure to high altitude may increase the risk of heart attack during waking and sleep. This study compared heart rate variability (HVR) and its components during sleep at low altitude and after 30 - 41 hours of acclimatization at high altitude $(3480 \mathrm{~m})$ in five mountain marathon runners controlled for diet, drugs, light-dark cycle and jet lag. In comparison to sea level, RR-intervals during sleep at high altitude decreased significantly $(\mathrm{P}<0.001)$. The significant increase in sympathetic autonomic cardiovascular modulation at high altitude protects against excessive oxygen deprivation during sleep. Increases in R-R intervals can require longer periods of acclimatization at $3480 \mathrm{~m}$ to mitigate the effects of altitude/hypoxia on sympathetic tone, thus reducing cardiovascular distress at rest during waking and sleep and probably before during and after athletic performance at altitude.
\end{abstract}

Keywords: Heart Rate Variability; Very Low Frequency Fluctuation (VLF, $<0.04 \mathrm{~Hz}$ ) Rhythm; Low-Frequency (LF, $0.04-0.15$ Hz) Rhythm; High-Frequency (HF, 0.15 - 0.4 Hz) Rhythm; Mountain Marathon Runners

\section{Introduction}

\subsection{Heart Rate Variability}

Intrinsic to pacemaker tissues, cardiac automaticity is regulated by the central nervous systems (CNS). Control of the cardiac cycle is also mediated by local and autonomic nervous system components: the parasympathetic influence on heart rate is modulated by acetylcholine released by the vagus nerve on the sinoatrial node and the sympathetic influence by the release of epinephrine and norepinephrine. Under resting conditions, vagal modulation and tone predominate at the level of the sinoatrial node. Vagal and sympathetic activities interact constantly [1 hereinafter Task Force 1996].

In the sympathovagal and thoracic systems, CNS control and influences on the autonomic mechanism can be physiologically and voluntarily cut off to different degrees during relaxed attentive waking and involuntarily during the progressive deepening of slow-wave sleep [1].

"Corresponding author.
Alterations in the autonomic nervous system may give rise to cardiovascular and/or cerebrovascular diseases and have been frequently associated with death in humans. Research into predisposition to arrhythmias and increased sympathetic activity or reduced vagal activity has led to the development of quantitative markers of autonomic activity [1].

The Task Force [1] has suggested that cardiovascular changes can be investigated non-invasively by electrocardiography (ECG) and by common parameters derived from ECG such as heart rate variability (HRV), i.e., the variation in the duration of two consecutive R-R intervals. $\mathrm{R}-\mathrm{R}$ interval variations during resting condition are precisely tuned by reflexes directed to the sinus node and modulated by central (vasomotor and respiratory centre) and peripheral (arterial pressure and respiratory movements) oscillators, particularly during high altitude exposure. Analysis of R-R intervals provides information about the state and function of central oscillators, sympathetic and vagal efferent activities, humoral cardiac factors, and sinus node characteristics [1]. 
It has also been reported by the Task Force [1] and by Lanfranchi et al. [2] that the risk of cardiac disease can be evaluated by means of spectral analysis of the variability in the R-R interval in order to determine highfrequency ([HF] $0.15-0.4 \mathrm{~Hz}$ ) rhythm, which primarily reflects respiratory-driven vagal modulation of sinus rhythm, and low-frequency ([LF] $0.04-0.15 \mathrm{~Hz}$ ) rhythm, which appears to have a widespread neuronal genesis. LF is also considered as a marker of sympathetic modulation (expressed in normalized units) and/or as a parameter that includes both sympathetic and vagal modulation. Thermoregulation-related HRV, so-called very low frequency fluctuation $([\mathrm{VLF}]<0.04 \mathrm{~Hz})$ rhythm is also used to analyze HRV. However, explanation of the VLF component of HRV is less defined than the LF or the HF component. VLF, LF and HF power are usually measured in absolute values of power (milliseconds squared $\left.\left[\mathrm{ms}^{2}\right]\right)$. LF and HF can be also measured in normalized units (NU) to emphasize the controlled and balanced behavior of the two branches of the autonomic nervous system, as well as baroreflex responsiveness to beat-to-beat variations in arterial blood pressure [1]. Normalization of LF and HF power tends to minimize the effect of the changes in the total power on the values of these two components. Normalized units and absolute values of LF and HF power should both be calculated to provide a better measurement of the degree of autonomic modulation rather than just the level of autonomic tone [1].

To date, little has been reported about the effect of different environments (type of nature, physical activity, emotional circumstances, environment of the group) on HRV analysis [1].

\subsection{Type of Nature}

\subsubsection{Hypobaric-Hypoxic Conditions}

Hypoxia affects ventilator control circuits and autonomic cardiovascular regulatory mechanisms in normal subjects and in those with cardiac and/or respiratory failure. In hypobaric-hypoxic conditions, HRV analysis can be considered as an expression of the changes in respiratory frequency oscillation and of respiratory sinus arrhythmia not mediated by the beta adrenergic block, yet modulated by the vagus nerve; furthermore, changes in the cardiac vagal nervous system result in proportional changes in R-R intervals. During exposure to hypobaric-hypoxic and during waking conditions, HRV is reduced, with a relative increase in the LF component. In mountaineers, the relative increase in the LF component is thought to be due to increased sympathetic modulation of the sinus node in response to high altitude. Acute exposure to hypobaric-hypoxic conditions at high altitude increases the risk of cardiovascular stroke, heart attack and death [2].

\subsubsection{Sleep-Wake Cycle}

At low altitudes, HR is normally higher during daytime hours and lower at night. During wakefulness, HRV oscillates in relation to physical activity; during the sleep cycle it changes with the passage from non-rapid eye movement (NREM) to rapid eye movement (REM) sleep to awakening periods during sleep (W) episodes [3]. Changes in HR may precede changes on the electroencephalogram (EEG). Shorter R-R intervals are believed to reflect sympathetic dominance and are associated with waking and REM sleep, while longer R-R intervals reflect vagal dominance probably coincident with sleep dampening. This allows for HRV analysis in the LF, HF, and LH:HF frequency domains as a tool for exploring sympathovagal balance continuously during sleep at altitude. To our knowledge, HRV during the nocturnal sleepwake cycle at high altitudes in humans has been less investigated than at low altitude in humans and animals.

\subsection{Environment and Physical Activity of Mountain Marathon Athletes}

Mountain marathoners, also called sky runners, are athletes who perform marathons and races at high altitude. Their anthropometric characteristics are similar to those of marathoners competing at sea level. Various physiological, biochemical, hematological and psychological parameters studied in these athletes during waking, before, during, and after races have shown that changes in these parameters are transient, promptly return to normal, and produce no evident clinical symptoms or diseases. The endurance performance of mountain marathoners is appreciably reduced at high altitude. Based on their antropometrical characteristics, mountain marathoners may be considered a suitable group for studying possible pathological effects of stay and exercise at altitude [4-13]. Unlike the situation described in Lanfranchi and coworkers [2], the medical staff involved in this study, during the long-term follow-up of a group of mountain marathon athletes during training and athletic competition from sea level to $5500 \mathrm{~m}$, has never recorded signs of acute mountain sickness (AMS) [4-13]. Regular exercise is thought to modify autonomic balance and accelerate the safe recovery of physiological sympathovagal interaction [1]. Exercise and training of the mountain marathon runners might have decreased their risk of cardiovascular mortality and sudden cardiac death at low and high altitudes, as well as prevented syncope episodes, which can occur after the end of races at high altitude [12].

\subsection{Mountain Environments}

When undertaken in mountain environments, studies on 
humans typically lack the controlled conditions of the laboratory. High-altitude research, as in the present study, is limited to a small number of anthropometrically controlled subjects. Even so, for future high and very high altitude expeditions, studies on anthropometrically controlled subjects transiently and naturally exposed to the mountain environment can give, albeit under less rigorously controlled conditions, important insights into HRV that may not completely be gleaned from sea-level laboratory studies. The data presented here were collected during sleep, in sea-level native mountain marathon runners, at $122 \mathrm{~m}$ and at an altitude of $3480 \mathrm{~m}$, in clinostatic position so as to avoid, or at least reduce, autonomic mechanisms correlated with the central and peripheral autonomic nervous systems and effects related to the time of eating, jet lag, light-dark cycle and motor activities [14].

\subsection{Aim of the Study}

Given the direct and indirect physiological effect of hypobaric-hypoxia on the cardiovascular system [15], fluctuations in autonomic cardiovascular regulation during exposure to high altitude [2], the increased risk of heart attack, and the instability of the cardiovascular system during sleep, this study analyzed HRV by calculating the average of the spectral component of stacked series of sequential power spectra from short ECG segments lasting 0.5 minutes [16] during sleep: at sea level and between 30 and $41 \mathrm{~h}$ of acclimatization at $3480 \mathrm{~m}$ altitude in a small sample of anthropometrically well characterized mountain marathon runners [4-13]. The analysis of HRV during sleep at $3480 \mathrm{~m}$ can provide firmer ground for studying and diagnosing overtraining at high altitude of mountain marathon runners exposed to hypobaric-hypoxic conditions. HRV measurements at high altitude may offer useful data for standard physiological evaluation and for formulating recommendations on increasing or reducing acclimatization time to defined hypobarichypoxic conditions and reduce cardiovascular distress at low altitude and during performance at high altitude in particular.

\section{Material and Methods}

\subsection{Environment of the Group}

Five adult mountain marathon runners, native to sea level, with at least 20 years experience of competitive races and climbing at altitudes between $122 \mathrm{~m}$ and $5500 \mathrm{~m}$, aged from 38 to 41 years, clinically and psychologically tested before, during and after competitions at high altitude $(>2500 \mathrm{~m})$ were recruited for this study [4-13].

The average body weight for the five subjects was $65.8 \pm 4 \mathrm{~kg}$; the average height was $176 \pm 3.7 \mathrm{~cm}$ and the average aerobic power was $61.4 \pm 2.7 \mathrm{ml} \cdot \mathrm{kg}^{-1} \cdot \mathrm{min}^{-1}$. The use of any drugs, dietary and neuroactive supplements was suspended for one week before the start of the study. Effects of light-dark and jet-lag interference on acclimatization were excluded by the location of the study.

\subsection{Polysomnographic Recording}

Polysomnographic recording procedures were carried out in accordance with Directive 86/609/EEC for experimental human care. Informed consent prior to each experimental session was given by all five subjects and by the international medical staff of the Federation of Sport at Altitude. The study was conducted during normal sleep time (between 10 p.m. and 9 a.m.). Workouts were suspended on the days the measurements were taken.

Polysomnographic recordings were taken in dedicated dark, isolated, silent rooms at $122 \mathrm{~m}$ (Milan, Italy) at a barometric pressure $\left(\mathrm{P}_{\mathrm{B}}\right)$ of $742 \pm 7.7 \mathrm{~mm} \mathrm{Hg}$ and after an acclimatization period of $30-32$ or $38-41 \mathrm{~h}$ after reaching $3480 \mathrm{~m}$ at a $\mathrm{P}_{\mathrm{B}}$ of $495.4 \pm 3.19 \mathrm{~mm} \mathrm{Hg}$. The recordings were performed to study the electroencephalogram (EEG), submental electromyogram (EMG), electrooculogram (EOG), electrocardiogram (ECG) and the percent of peripheral arterial oxygen saturation $\left(\% \mathrm{SpaO}_{2}\right)$ signals. All signals were amplified and registered at a sampling rate of $250 \mathrm{~Hz}$, then analyzed off-line according to standard criteria (Somnological 3, EmblaMedcare, Flaga $^{\circledR}$, Monza, Italy). Electrocardiographic recordings were taken with a bipolar derivation from two cardiac electrodes placed in $\mathrm{V}_{2}$ in the fourth left intercostal region along the sternum, and in $\mathrm{V}_{4}$ in the fifth left intercostal region on the hemiclavear line.

The polysomnographic tracings containing the ECG signals were scored as follows: awakening during sleep (W), S1 + S2 and S3 + S4 of slow-wave sleep, also called NREM sleep, and REM sleep, according to standard criteria developed by Rechtschaffen and Kales [17] in 30-second artifact-free epochs [16].

Automatic analysis of HRV values was performed using Somnological 3 software $\left(\right.$ Embla $^{\circledR}$ ), autoregressive model, order 12, following the rules of the Task Force [1] in a total of stacked series of sequential 30-second artifact-free epochs of awakening during sleep (W), S1 + S2 and S3 + S4 of NREM sleep, and of REM sleep.

This analysis focused on the average of the R-R intervals, the power of the very low frequency (VLF), low frequency (LF) and high frequency (HF), the normalized unit of the low Frequency and high frequency $\left(\mathrm{LF}_{\mathrm{RR}} \mathrm{NU}\right.$ and $\mathrm{HF}_{\mathrm{RR}} \mathrm{NU}$ ), which were obtained by dividing the power of each component by the total variance, from which the VLF was subtracted, and by multiplying them by 100 , and on the total power (TP) [Task Force 1]. 


\subsection{Statistical Analysis}

The results are expressed as the mean \pm standard deviation (SD) or standard error mean (SEM). Probabilities lower than $\mathrm{P}<0.05$ were accepted as significant. ANOVA and post hoc tests were also performed. Simple linear regression analysis between the $\left(\% \mathrm{SpaO}_{2}, \mathrm{PCO}_{2}\right)$ (personal observations) and the ECG parameters was also performed using the Stat-View program.

\section{Results}

None of the five subjects ever experienced AMS during the present study. There were no differences in the time of evaluation of the subjects. During sleep the $\% \mathrm{SpaO}_{2}$ and $\mathrm{PCO}_{2}$ at high altitude was significantly lower than that recorded at sea level (average $\pm \mathrm{SD}: \% \mathrm{SpaO}_{2} 80 \pm$ 3.64 at $3480 \mathrm{~m}$ vs $95.6 \pm 0.85$ at $122 \mathrm{~m} ; \mathrm{P}<0.05 ; \mathrm{PCO}_{2}$ : $28.25 \pm 2.33$ at $3480 \mathrm{~m}$ vs $41.21 \pm 3.38$ at $122 \mathrm{~m}$ ).

\subsection{R-R Intervals (ms)}

\subsubsection{Sea Level (122 m)}

At $122 \mathrm{~m}$, the averages of the recorded R-R intervals were similar between all sleep stages and ranged from $1223 \mathrm{~ms}$ during the awakening period during sleep (W), $1300 \mathrm{~ms}$ during S1 + S2 and $1262 \mathrm{~ms}$ during S3 + S4 of NREM sleep, to $1272 \mathrm{~ms}$ during REM sleep (Table 1). The averages of the R-R intervals recorded at $122 \mathrm{~m}$ during the nocturnal sleep-wake cycle suggested a prevalence of vagal tone during all four sleep stages and in all five subjects.

\subsubsection{High Altitude $(3480 \mathrm{~m})$}

At $3480 \mathrm{~m}$, the averages of the R-R intervals recorded during sleep ranged from $935 \mathrm{~ms}$ during $\mathrm{W}, 1054 \mathrm{~ms}$ during S1 + S2 and $993 \mathrm{~ms}$ during S3 + S4 of NREM sleep, to $990 \mathrm{~ms}$ during REM sleep.

The averages of the R-R intervals recorded at altitude during the awakening period during sleep (W: $935 \pm 88$ ) were significantly shorter than those recorded during S1 + S2 $(1054 \pm 73 ; \mathrm{P}<0.05)$ (Table 1). The averages of the R-R intervals recorded during sleep suggested an increase in sympathetic tone during $\mathrm{W}, \mathrm{S} 3+\mathrm{S} 4$ NREM sleep and REM sleep, and a persistent significant increase in vagal tone during the light phases of NREM sleep.

\subsubsection{Sea Level $(122 \mathrm{~m})$ and High Altitude $(3480 \mathrm{~m})$}

Changes in ECG, with a reduction in the R-R intervals (ms) recorded during sleep, became evident between 30 and $41 \mathrm{~h}$ of acclimatization at $3480 \mathrm{~m}$ compared to measurements taken at $122 \mathrm{~m}$ during sleep: signs of sinus arrhythmia during periodic breathing; during S1 + S2 of
NREM sleep, and during REM sleep were evident (Table 1). In all five mountain marathon runners, the averages of the R-R intervals during $\mathrm{W}, \mathrm{S} 1+\mathrm{S} 2$ and $\mathrm{S} 3+\mathrm{S} 4$ of NREM sleep, and REM sleep were significantly shorter at altitude than those recorded at sea level $(\mathrm{P}<0.01$ $\mathrm{P}<0.001)$.

The averages of the R-R intervals during W $(935 \pm 88)$, $\mathrm{S} 1+\mathrm{S} 2(1054 \pm 73)$ and S3 + S4 (993 \pm 55) of NREM sleep, and REM sleep $(990 \pm 68)$ were significantly shorter at altitude than those recorded at sea level [(W: $1223 \pm 102 ; \mathrm{P}<0.001) ;(\mathrm{S} 1+\mathrm{S} 2: 1300 \pm 69 ; \mathrm{P}<0.001)$; (S3 + S4: $1262 \pm 65 ; \mathrm{P}<0.001)$; (REM: $1272 \pm 77 ; \mathrm{P}<$ $0.001)]$. The averages of the R-R intervals suggested a prevalence of sympathetic tone during all sleep stages at altitude and a prevalence of vagal tone during sleep at sea level.

Simple regression analysis between the average $\% \mathrm{SpaO}_{2}$ during sleep at low and at high altitudes was significantly correlated $\left(\mathrm{DF}_{1,9}\right.$ R-squared 0.477 , coefficient 623.58, F-test $_{7,31}, \mathrm{P}=0.0269, \mathrm{t}=2.704$ ) with the average changes in $\mathrm{R}-\mathrm{R}$ intervals.

\subsection{Total Power of Very Low Frequency [(VLF, $\left.\left.\mathrm{ms}^{2}\right)(<0.04 \mathrm{~Hz})\right] \mathrm{vs}$ Thermoregulation-Related HRV}

\subsubsection{Sea Level (122 $\mathrm{m})$}

At $122 \mathrm{~m}$, the averages of VLF were: $22,455 \mathrm{~ms}^{2}$ during $\mathrm{W} ; 10,217 \mathrm{~ms}^{2}$ during S1 + S2; $3977 \mathrm{~ms}^{2}$ during S3 + S4, and $17,016 \mathrm{~ms}^{2}$ during REM sleep. The average VLF analyzed in 190 30-second epochs during the awakening period during sleep (W: $22,455 \pm 17,267$ ) was significantly longer than the average VLF analyzed in 226 30 -second signal epochs during S3 + S4 of NREM sleep (3977 $\pm 3531 ; \mathrm{P}<0.0046)$ (Table 2). The average VLF analyzed in 22630 -second epochs during S3 + S4 of NREM sleep $(3977 \pm 3531)$ was significantly shorter than that analyzed in 17530 -second epochs during REM sleep $(17,016 \pm 13,612 ; \mathrm{P}<0.009)$.

These data collected at $122 \mathrm{~m}$ above sea level indicate that during the deepening of synchronized sleep the thermoregulation-related component (VLF) of HRV decreased, with an increase in vagal tone. The averages of VLF during REM sleep increased, approaching the average recorded during $\mathrm{W}$, thus suggesting a high level of sympathetic tone during both stages (W and REM).

\subsubsection{High Altitude $(3480 \mathrm{~m})$}

At $3480 \mathrm{~m}$, the averages of VLF were: $17,539 \mathrm{~ms}^{2}$ during $\mathrm{W} ; 8452 \mathrm{~ms}^{2}$ during S1 + S2 of NREM sleep; $3179 \mathrm{~ms}^{2}$ during S3 + S4 of NREM sleep; and 15,765 $\mathrm{ms}^{2}$ during REM sleep.

The average VLF recorded in 27130 -second epochs 
Table 1. Averages of the R-R intervals (ms) analysed in 5 altitude marathon runners, recorded in 30-second physiologically defined number of signal epochs according to the standard criteria developed by Rechtschaffen and Kales (1968) during the waking periods during sleep (W), stages S1 + S2 and S3 + S4 of NREM sleep and REM sleep, at $122 \mathrm{~m}$ and after 30 - $41 \mathrm{~h}$ of acclimatisation at $3480 \mathrm{~m} .^{(1)}$

\begin{tabular}{|c|c|c|c|c|c|c|c|c|c|}
\hline \multirow[t]{2}{*}{ Stages } & \multirow[t]{2}{*}{ Subjects } & \multicolumn{3}{|c|}{$122 \mathrm{~m}$} & \multicolumn{3}{|c|}{$3480 \mathrm{~m}$} & \multirow[b]{3}{*}{ Delta } & \multirow[b]{3}{*}{$P$ value } \\
\hline & & Epochs & & & Epochs & & & & \\
\hline \multicolumn{2}{|c|}{ Awakening during sleep } & N. & Mean & S.D. & N. & Mean & S.D. & & \\
\hline & C.S & 7 & 1212 & 56 & 35 & 1007 & 72 & -205 & 0.0001 \\
\hline & M.R. & 3 & 1051 & 76 & 3 & 817 & 37 & -234 & 0.0087 \\
\hline & G.M. & 13 & 1362 & 81 & 12 & 1061 & 203 & -301 & 0.0001 \\
\hline & D.C. & 140 & 1026 & 73 & 157 & 779 & 36 & -247 & 0.0001 \\
\hline & S.S. & 27 & 1463 & 224 & 64 & 1011 & 93 & -452 & 0.0001 \\
\hline & No. of epochs & 190 & & & & & & & \\
\hline & & No. of subjects & Mean & $\begin{array}{l}\text { S.E.M. } \\
\text { subjects }\end{array}$ & No. of subjects & Mean & $\begin{array}{c}\text { S.E.M. } \\
\text { subjects }\end{array}$ & Delta & \\
\hline & Average & 5 & 1223 & 102 & 5 & 935 & 88 & -278 & 0.001 \\
\hline \multirow[t]{10}{*}{$S 1+S 2$} & & Epochs & & & Epochs & & & & \\
\hline & & N. & Mean & S.D. & N. & Mean & S.D. & Delta & $P$ value \\
\hline & C.S & 45 & 1281 & 60 & 34 & 1123 & 67 & -158 & 0.0001 \\
\hline & M.R. & 58 & 1130 & 55 & 52 & 878 & 41 & -252 & 0.0001 \\
\hline & G.M. & 53 & 1497 & 71 & 54 & 1236 & 86 & -261 & 0.0001 \\
\hline & D.C. & 302 & 1096 & 43 & 322 & 835 & 28 & -261 & 0.0001 \\
\hline & S.S. & 200 & 1494 & 115 & 237 & 1197 & 145 & -297 & 0.0001 \\
\hline & No. of epochs & 658 & & & 699 & & & & \\
\hline & & No. of subjects & Mean & $\begin{array}{c}\text { S.E.M. } \\
\text { subjects }\end{array}$ & No. of subjects & Mean & $\begin{array}{c}\text { S.E.M. } \\
\text { subjects }\end{array}$ & Delta & \\
\hline & Average & 5 & 1300 & 69 & 5 & 1054 & 73 & -246 & 0.0001 \\
\hline \multirow[t]{10}{*}{$S 3+S 4$} & & Epochs & & & Epochs & & & & \\
\hline & & N. & Mean & S.D. & N. & Mean & S.D. & Delta & $P$ value \\
\hline & C.S & 16 & 1277 & 48 & 9 & 1054 & 29 & -223 & 0.0001 \\
\hline & M.R. & 11 & 1121 & 42 & 6 & 833 & 8 & -288 & 0.0001 \\
\hline & G.M. & 9 & 1435 & 113 & 7 & 1165 & 112 & -270 & 0.0003 \\
\hline & D.C. & 98 & 1065 & 55 & 25 & 846 & 20 & -219 & 0.0001 \\
\hline & S.S. & 92 & 1410 & 65 & 59 & 1068 & 106 & -342 & 0.0001 \\
\hline & No. of epochs & 226 & & & 106 & & & & \\
\hline & & No. of subjects & Mean & $\begin{array}{c}\text { S.E.M. } \\
\text { subjects }\end{array}$ & No. of subjects & Mean & $\begin{array}{l}\text { S.E.M. } \\
\text { subjects }\end{array}$ & Delta & \\
\hline & Average & 5 & 1262 & 65 & 5 & 993 & 55 & -268 & 0.001 \\
\hline \multirow[t]{10}{*}{ REM } & & Epochs & & & Epochs & & & & \\
\hline & & N. & Mean & S.D. & N. & Mean & S.D. & Delta & $P$ value \\
\hline & C.S & 8 & 1276 & 73 & 5 & 1128 & 120 & -147 & 0.0178 \\
\hline & M.R. & 23 & 1085 & 69 & 13 & 813 & 25 & -272 & 0.0001 \\
\hline & G.M. & 10 & 1450 & 60 & 13 & 1106 & 88 & -344 & 0.0001 \\
\hline & D.C. & 62 & 1062 & 56 & 30 & 832 & 40 & -231 & 0.0001 \\
\hline & S.S. & 72 & 1485 & 125 & 52 & 1069 & 67 & -416 & 0.0001 \\
\hline & No. of epochs & 175 & & & & & & & \\
\hline & & No. of subjects & Mean & $\begin{array}{c}\text { S.E.M. } \\
\text { subjects }\end{array}$ & No. of subjects & Mean & $\begin{array}{c}\text { S.E.M. } \\
\text { subjects }\end{array}$ & Delta & \\
\hline & Average & 5 & 1272 & 77 & 5 & 990 & 68 & -282 & 0.001 \\
\hline
\end{tabular}

Footnotes to Table 1: ${ }^{(1)}$ One-way ANOVA tracts analysed in the five mountain runners: the averages of the R-R intervals (ms) measured during the W, S1 + S2, $\mathrm{S} 3+\mathrm{S} 4$ and REM sleep states were significantly different $(\mathrm{DF} 7,32,39$ : F-tests $=4.007, \mathrm{P}=0.003)$. The post-hoc comparison with Fisher analysis showed a significant difference $(\mathrm{P}<0.05)$ between the average of the R-R intervals recorded during $\mathrm{W}$ at $122 \mathrm{~m}$ and that at $3480 \mathrm{~m}$, and a significant difference between the average of the R-R intervals recorded during stages S3 + S4 at $3480 \mathrm{~m}$ and during REM sleep at $3480 \mathrm{~m}(\mathrm{P}<0.05)$. The average of the R-R intervals recorded during $\mathrm{W}$ at $3480 \mathrm{~m}$ differed significantly from that during stages $\mathrm{S} 1+\mathrm{S} 2$ at $122 \mathrm{~m}(\mathrm{P}<0.05)$. Post-hoc comparison with Fisher analysis showed that the average of the R-R intervals recorded during stages S3 + S4 at $122 \mathrm{~m}$ differed significantly from that during REM sleep at $122 \mathrm{~m}(\mathrm{P}<0.05)$. The average of the R-R intervals recorded during stages S1 + S2 at $122 \mathrm{~m}$ differed significantly from that during stages S1 + S2 at $3480 \mathrm{~m}(\mathrm{P}<0.05)$. Post-hoc comparison of the average of the R-R intervals recorded during stages S1 + S2 at $122 \mathrm{~m}$ differed significantly from that during S3 $+\mathrm{S} 4$ and $\mathrm{REM}$ sleep at $3480 \mathrm{~m}(\mathrm{P}<0.05)$. Fisher analysis demonstrated that the average of the R-R intervals recorded during stages S3 + S4 at $3480 \mathrm{~m}$ differed significantly from that during REM sleep at $122 \mathrm{~m}(\mathrm{P}<0.05)$. There was a significant difference between the R-R intervals recorded during REM sleep at $122 \mathrm{~m}$ and those during REM sleep at $3480 \mathrm{~m}$ $(\mathrm{P}<0.05)$. "Post-hoc comparison with Student's t-test showed that the average of the power of the R-R interval tract analysed in 27130 -second epochs during the waking period during sleep (W) at $3480 \mathrm{~m}$ was significantly lower $(\mathrm{P}<0.05)$ than the average measured in 69930 -second epochs during stages $\mathrm{S} 1+\mathrm{S} 2$ of NREM sleep at $3480 \mathrm{~m}$ in all 5 subjects. 
Table 2. Averages of the total power of very low frequency $\left(\mathrm{VLF}, \mathrm{ms}^{2}\right)(<0.04 \mathrm{~Hz})$ (thermoregulation-related HRV) recorded in 30-second signal epochs physiologically defined according to standard criteria developed by Rechtschaffen and Kales (1968), during waking periods during sleep (W), stages S1 + S2 and S3 + S4 of NREM and REM sleep, at $122 \mathrm{~m}$ and after 30 $41 \mathrm{~h}$ of acclimatisation at $3480 \mathrm{~m}$ in the five subjects. ${ }^{(1)}$

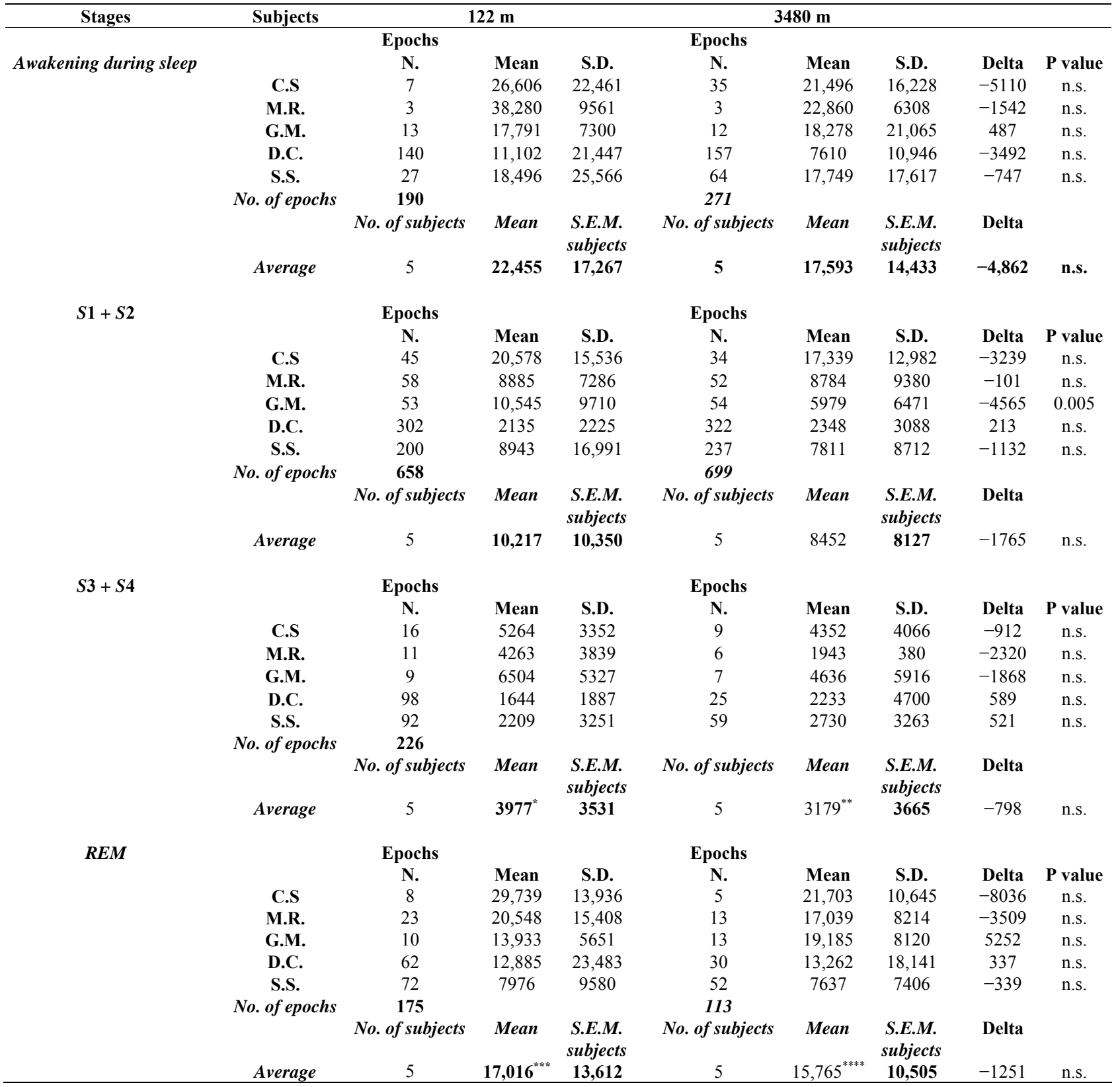

Footnotes to Table 2: ${ }^{(1)}$ One-way ANOVA showed that in the five subjects the averages of the total power of very low frequency $\left(\mathrm{VLF}, \mathrm{ms}^{2}\right)(<0.04 \mathrm{~Hz})($ thermoregulation-related HRV) differed significantly between stages ( $\mathrm{DF}=7,32,39 ; \mathrm{F}=5.15 ; \mathrm{P}<0.0002)$. Post-hoc comparison with Fisher analysis of the mean revealed a significant difference between the VLF values recorded during $\mathrm{W}$ at $122 \mathrm{~m}$ and those during stages $\mathrm{S} 1+\mathrm{S} 2$ at $122 \mathrm{~m}(\mathrm{P}<0.05)$, and a significant difference between the VLF values recorded during stages S1 + S2 at $3480 \mathrm{~m}$ and those during stages S3 + S4 at $122 \mathrm{~m}$ and S3 + S4 at $3480 \mathrm{~m}$. There was also a significant difference between the mean of the VLF recorded during stages S3 + S4 at $122 \mathrm{~m}$ and those during REM sleep at $122 \mathrm{~m}$ and at $3480 \mathrm{~m}(\mathrm{P}<0.05)$. There was a significant difference between the average of the VLF recorded during stages S3 $+\mathrm{S} 4$ at $3480 \mathrm{~m}$ and those during REM sleep at $122 \mathrm{~m}$ and at 3480 $\mathrm{m}(\mathrm{P}<0.05)$. 'Post-hoc comparison with Student'S t-test showed that the power in the VLF range of the R-R intervals measured in 19030 -second epochs during the waking period during sleep $(\mathrm{W})$ at $122 \mathrm{~m}$ was significantly higher $(\mathrm{P}<0.0046)$ than that measured in 22630 -second signal epochs during stages $\mathrm{S} 3+\mathrm{S} 4$ of NREM sleep at $122 \mathrm{~m}$ in all five subjects. ${ }^{* *}$ Post-hoc comparison with Student's t-test of the mean of the average of the power in the VLF range measured in 27130 -second epochs during the awakening period during sleep (W) at $3480 \mathrm{~m}$ was significantly higher $(\mathrm{P}<0.0007)$ than that measured in 10630 -second signal epochs during stages S3+S4 of NREM sleep at $3480 \mathrm{~m}$ in all five subjects. ${ }^{* * *}$ Post-hoc comparison with Student's t-test of the mean of the average of the power in the VLF range measured in 22630 -second epochs during stages S3 + S4 of NREM sleep at 122 m was significantly lower (P $<0.009$ ) than that measured in 17530 -second epochs during REM sleep at $122 \mathrm{~m}$ in all five subjects. ${ }^{* * * *}$ Post-hoc comparison with Student's t-test of the mean of the average of the power in the VLF range measured in 10630 -second epochs during stages S3 + S4 of NREM sleep at $3480 \mathrm{~m}$ was significantly lower (P < 0.001$)$ than that measured in 11330 -second epochs during REM sleep at $3480 \mathrm{~m}$ in all five subjects. 
during the awakening period during sleep [(W) $(17,593 \pm$ 14,433)] was significantly longer than the average VLF recorded in 10630 -second signal epochs during S3 + S4 of NREM sleep $(3179 \pm 3665 ; \mathrm{P}<0.0007)$ (Table 2). The average VLF in 10630 -second epochs during S3 + S4 of NREM sleep (3179 \pm 3665$)$ was significantly shorter than that analyzed in 11330 -second epochs of REM sleep $(15,765 \pm 10,505 ; \mathrm{P}<0.05)$.

Overall, the averaged data recorded during sleep at $3480 \mathrm{~m}$ demonstrate that during the deepening of synchronized sleep the thermoregulation-related component (VLF) of HRV decreased, with a physiological increase in vagal tone. During REM sleep the thermoregulationrelated component of HRV approached that recorded during the awakening period during sleep (W) indicating an increase in the sympathetic tone .

\subsubsection{Sea Level $(122 \mathrm{~m})$ and High Altitude $(3480 \mathrm{~m})$}

The average of the total power of very low frequency $\left(\mathrm{VLF}, \mathrm{ms}^{2}\right.$ ) recorded during S1 + S2 of NREM sleep $(5979 \pm 6471)$ was significantly shorter at high altitude than that recorded sea level $(10,545 \pm 9710 ; \mathrm{P}<0.005)$ in only 1/5 (GM) mountain marathon runners (Table 2).

\subsection{Total Power of Low Frequency [(LF, $\left.\mathrm{ms}^{2}\right)$ (0.04 - 0.15 Hz)] Range. The LF Appears to Have a Widespread Neuronal Genesis and Is Considered as a Marker of Sympathetic Modulation or a Marker of Both Sympathetic and Vagal Modulation}

\subsubsection{Sea Level ( $122 \mathrm{~m})$}

At $122 \mathrm{~m}$, the averages of LF were: $7997 \mathrm{~ms}^{2}$ during W; $7400 \mathrm{~ms}^{2}$ during S1 + S2; $4881 \mathrm{~ms}^{2}$ during S3 + S4; and $8579 \mathrm{~ms}^{2}$ during REM sleep. The changes in the average total power in LF were significantly shorter during S3 + S4 than those observed during REM sleep (4881 \pm 2041 vs $8579 \pm 3473 ; \mathrm{P}<0.02$ ) (Table 3). These data suggest that the average values of LF, a marker of sympathetic modulation, decreased during the deepening phases of NREM sleep. During REM sleep the average values of LF significantly increased, approaching a value similar to that observed during $\mathrm{W}$.

\subsubsection{High Altitude (3480 m)}

At $3480 \mathrm{~m}$, the averages of LF were: $6272 \mathrm{~ms}^{2}$ during W; $7516 \mathrm{~ms}^{2}$ during S1 + S2; $3805 \mathrm{~ms}^{2}$ during S3 + S4; and $5715 \mathrm{~ms}^{2}$ during REM sleep (Table 3). The results demonstrate that the average values of LF during sleep at altitude did not change significantly between the different sleep stages (Table 3).

\subsubsection{Sea Level (122 $\mathrm{m})$ and High Altitude (3480 m)} The averages of total power of low frequency $\left(\mathrm{LF} \mathrm{ms}^{2}\right.$ ) recorded at high altitude during $\mathrm{W}$ were significantly shorter than those recorded at sea level in $3 / 5$ subjects [(CS: $3163 \pm 1400$ at $3480 \mathrm{~m}$ vs $5148 \pm 3163$ at $122 \mathrm{~m}$; P < 0.0074); (GM: $6157 \pm 2271$ at $3480 \mathrm{~m}$ vs $9656 \pm 2978$ at $122 \mathrm{~m}$; $\mathrm{P}<0.0033$ ); (DC: $2774 \pm 2056$ at $3480 \mathrm{~m}$ vs $5083 \pm 4655$ at $122 \mathrm{~m} ; \mathrm{P}<0.0001)$ ] (Table 3). The average $\mathrm{LF}$ recorded during $\mathrm{S} 1+\mathrm{S} 2$ was significantly longer at altitude than that recorded at sea level in $1 / 5$ subjects (SS: $17,947 \pm 12,895$ at $3480 \mathrm{~m}$ vs $10,155 \pm 6434$ at 122 $\mathrm{m}$; $\mathrm{P}<0.0001$ ); the LF was significantly shorter in $2 / 5$ subjects [(CS: $3539 \pm 1734$ at $3480 \mathrm{~m}$ vs $5946 \pm 2294$ at $122 \mathrm{~m}$; $\mathrm{P}<0.0001$ ); (MR: $6059 \pm 1641$ at $3480 \mathrm{~m}$ vs $10,118 \pm 2699$ at $122 \mathrm{~m} ; \mathrm{P}<0.0001)]$; the average LF recorded during $\mathrm{S} 3+\mathrm{S} 4$ was significantly shorter at altitude than that recorded at $122 \mathrm{~m}$ in $2 / 5$ [(CS: 2,276 \pm 2427 at $3480 \mathrm{~m}$ vs $3760 \pm 1098$ at $122 \mathrm{~m}$; $\mathrm{P}<0.0455$ ); (MR: $3917 \pm 592$ at $3480 \mathrm{~m}$ vs $8344 \pm 222$ at $122 \mathrm{~m}$; P < $0.0003)]$; the average LF recorded during REM sleep was significantly shorter at altitude than that recorded at sea level in 3/5 subjects [(MR: $5200 \pm 1513$ at $3480 \mathrm{~m}$ vs $10159 \pm 2790$ at $122 \mathrm{~m} ; \mathrm{P}<0.0001$ ); (DC: $3702 \pm 1955$ at $3480 \mathrm{~m}$ vs $6727 \pm 4144$ at $122 \mathrm{~m}$; P < 0.0003); (SS: 5, $140 \pm 4402$ at $3480 \mathrm{~m}$ vs $11,509 \pm 6775$ at $122 \mathrm{~m}$; P < $0.0001)]$. These data demonstrate great variability in the sympathetic LF component of HRV recorded at low and high altitudes in the five mountain marathon runners.

\subsection{Low-Frequency in Normalized Units $\left[\left(\mathrm{LF}_{\mathrm{RR}} \mathrm{NU}\right)(0.04-0.15 \mathrm{~Hz})\right]$ Range. $\mathrm{LF}_{\mathrm{RR}} \mathrm{NU}$ Is Considered as a Marker of Sympathetic Modulation}

\subsubsection{Sea Level (122 m)}

In all 5 subjects, the average $\mathrm{LF}_{\mathrm{RR}} \mathrm{NU}$ recorded in 190 30 -second epochs during the awakening period during sleep (W: $73.41 \pm 10.15$ ) differed significantly from that recorded in 22630 -second epochs during S3 $+\mathrm{S} 4$ of NREM sleep $(64.76 \pm 11.45$; $\mathrm{P}<0.03)$. In all five mountain marathon runners, the average $\mathrm{LF}_{\mathrm{RR}} \mathrm{NU}$ during REM sleep was significantly longer $(74.32 \pm 10.17)$ than that observed during S3 + S4 (64.76 $\pm 11.45 ; \mathrm{P}<0.0192)$ (Table 4). These data indicate that the marker of sympathetic modulation $\left(\mathrm{LF}_{\mathrm{RR}} \mathrm{NU}\right)$ decreased during deepening of sleep. During REM sleep, the average value of $\mathrm{LF}_{\mathrm{RR}} \mathrm{NU}$ was similar to that recorded during the awakening period during sleep (W), suggesting that both desynchronized states were supported by an increase in sympathetic tone.

\subsubsection{High Altitude ( $3480 \mathrm{~m})$}

At $3480 \mathrm{~m}$, the average $\mathrm{LF}_{\mathrm{RR}} \mathrm{NU}$ values recorded during all four stages of sleep were similar and ranged from 75.77 during $\mathrm{W}, 76.25$ during $\mathrm{S} 1+\mathrm{S} 2,66.62$ during S3 + S4, to 80.97 during REM sleep (Table 4). 
Table 3. Averages of the total power in the low frequency $\left(\mathrm{LF}, \mathrm{ms}^{2}\right)(0.04-0.15 \mathrm{~Hz})$ range appear to have a widespread neuronal genesis and are considered as a marker of sympathetic modulation or a marker of both sympathetic and vagal modulation. The LF average was calculated in a physiologically defined number of 30-second signal epochs, defined according to the standard criteria developed by Rechtschaffen and Kales (1968), recorded during the waking period during sleep (W), stages $\mathrm{S} 1+\mathrm{S} 2$ and S3 + S4 of NREM and REM sleep at $122 \mathrm{~m}$ and after $30-41 \mathrm{~h}$ of acclimatisation at $3480 \mathrm{~m}$ in the five subjects. ${ }^{(1)}$

\begin{tabular}{|c|c|c|c|c|c|c|c|c|c|}
\hline \multirow[b]{3}{*}{ Awakening during sleep } & \multirow[t]{2}{*}{ Subjects } & \multicolumn{3}{|c|}{$122 \mathrm{~m}$} & \multicolumn{3}{|c|}{$3480 \mathrm{~m}$} & \multirow[b]{3}{*}{ Delta } & \multirow[b]{3}{*}{$P$ value } \\
\hline & & Epochs & & & Epochs & & & & \\
\hline & & N. & Mean & S.D. & N. & Mean & S.D. & & \\
\hline & C.S & 7 & 5148 & 2849 & 35 & 3163 & 1400 & -1985 & 0.0074 \\
\hline & M.R. & 3 & 10,477 & 3742 & 3 & 6780 & 428 & -3697 & n.s. \\
\hline & G.M. & 13 & 9656 & 2978 & 12 & 6157 & 2271 & -3499 & 0.0033 \\
\hline & D.C. & 140 & 5083 & 4655 & 157 & 2774 & 2056 & -2309 & 0.0001 \\
\hline & S.S. & 27 & 9619 & 4825 & 64 & 12,485 & 10,724 & 2866 & n.s. \\
\hline & No. of epochs & 190 & & & 271 & & & & \\
\hline & & No. of subjects & Mean & $\begin{array}{c}\text { S.E.M. } \\
\text { subjects }\end{array}$ & No. of subjects & Mean & $\begin{array}{c}\text { S.E.M. } \\
\text { subjects }\end{array}$ & Delta & \\
\hline & Average & 5 & 7997 & 3810 & 5 & 6272 & 3376 & -1725 & n.s \\
\hline \multirow[t]{10}{*}{$S 1+S 2$} & & Epochs & & & Epochs & & & & \\
\hline & & N. & Mean & S.D. & N. & Mean & S.D. & Delta & $P$ value \\
\hline & C.S & 45 & 5946 & 2294 & 34 & 3539 & 1734 & -2407 & 0.0001 \\
\hline & M.R. & 58 & 10,118 & 2699 & 52 & 6059 & 1641 & -4059 & 0.0001 \\
\hline & G.M. & 53 & 7692 & 2871 & 54 & 6998 & 2317 & -694 & $\mathrm{n} . \mathrm{s}$ \\
\hline & D.C. & 302 & 3090 & 1733 & 322 & 3036 & 1593 & -54 & $\mathrm{n} . \mathrm{s}$ \\
\hline & S.S. & 200 & 10,155 & 6434 & 237 & 17,947 & 12,895 & 7792 & 0.0001 \\
\hline & No. of epochs & 658 & & & 699 & & & & \\
\hline & & No. of subjects & Mean & $\begin{array}{c}\text { S.E.M. } \\
\text { subjects }\end{array}$ & No. of subjects & Mean & $\begin{array}{c}\text { S.E.M. } \\
\text { subjects }\end{array}$ & Delta & \\
\hline & Average & 5 & 7400 & 3206 & 5 & 7516 & 4036 & 116 & n.s. \\
\hline \multirow[t]{10}{*}{$S 3+S 4$} & & Epochs & & & Epochs & & & & \\
\hline & & N. & Mean & S.D. & N. & Mean & S.D. & Delta & $P$ value \\
\hline & C.S & 16 & 3760 & 1098 & 9 & 2276 & 2427 & -1484 & 0.0455 \\
\hline & M.R. & 11 & 8344 & 2222 & 6 & 3917 & 592 & -4427 & 0.0003 \\
\hline & G.M. & 9 & 4352 & 1275 & 7 & 4274 & 1504 & -78 & n.s. \\
\hline & D.C. & 98 & 2626 & 2066 & 25 & 2315 & 1056 & -311 & n.s. \\
\hline & S.S. & 92 & 5324 & 6544 & 59 & 6245 & 6031 & 921 & n.s. \\
\hline & No. of epochs & 226 & & & 106 & & & & \\
\hline & & No. of subjects & Mean & $\begin{array}{c}\text { S.E.M. } \\
\text { subjects }\end{array}$ & No. of subjects & Mean & $\begin{array}{c}\text { S.E.M. } \\
\text { subjects }\end{array}$ & Delta & \\
\hline & Average & 5 & 4881 & 2041 & 5 & 3805 & 2322 & $-1,076$ & n.s \\
\hline \multirow[t]{10}{*}{ REM } & & Epochs & & & Epochs & & & & \\
\hline & & N. & Mean & S.D. & N. & Mean & S.D. & Delta & $P$ value \\
\hline & C.S & 8 & 6497 & 1748 & 5 & 6105 & 2640 & -392 & n.s. \\
\hline & M.R. & 23 & 10,159 & 2790 & 13 & 5200 & 1513 & -4959 & 0.0001 \\
\hline & G.M. & 10 & 8005 & 1910 & 13 & 8430 & 2376 & 425 & n.s. \\
\hline & D.C. & 62 & 6727 & 4144 & 30 & 3702 & 1995 & -3025 & 0.0003 \\
\hline & S.S. & 72 & 11,509 & 6775 & 52 & 5140 & 4402 & -6369 & 0.0001 \\
\hline & No. of epochs & 175 & & & & & & & \\
\hline & & No. of subjects & Mean & $\begin{array}{c}\text { S.E.M. } \\
\text { subjects }\end{array}$ & No. of subjects & Mean & $\begin{array}{c}\text { S.E.M. } \\
\text { subjects }\end{array}$ & Delta & \\
\hline & Average & 5 & $8579^{*}$ & 3473 & 5 & 5715 & 2585 & -2864 & n.s \\
\hline
\end{tabular}

Footnotes to Table 3: ${ }^{(1)}$ One-way ANOVA revealed no significant changes in the averages of the total power in the low frequency $\left(\mathrm{LF}, \mathrm{ms}^{2}\right)(0.04-0.15 \mathrm{~Hz})$ range (DF 7,32,39, F test $1,3, \mathrm{P}=0,2819)$. " Post-hoc comparison with Student's t-test of the average LF value recorded in 17530 -second epochs during REM sleep at sea level was significantly higher $(\mathrm{P}<0.02)$ than that recorded in 22630 -second epochs during stages $\mathrm{S} 3+\mathrm{S} 4$ of NREM sleep at $122 \mathrm{~m}$ in all five subjects. 
Table 4. Averages of the total power in the low frequency $(0.04-0.15 \mathrm{~Hz})$ range in normalized units $\left(\mathrm{LF}-\mathrm{RR}_{\mathrm{R}}-\mathrm{NU}\right)$, which is considered as a marker of sympathetic modulation, measured in a physiologically defined number of 30-second signal epochs, defined according to the standard criteria developed by Rechtschaffen and Kales (1968), recorded during the waking period during sleep $(\mathrm{W})$, stages $\mathrm{S1}+\mathrm{S2}$ and S3 + S4 of NREM and REM sleep at $122 \mathrm{~m}$ and after 30 - 41 h of acclimatisation at 3480 $m$ in the five subjects. ${ }^{(1)}$

\begin{tabular}{|c|c|c|c|c|c|c|c|c|c|}
\hline \multirow[b]{3}{*}{ Awakening during sleep } & \multirow[t]{3}{*}{ Subjects } & \multicolumn{3}{|c|}{$122 \mathrm{~m}$} & \multicolumn{3}{|c|}{$3480 \mathrm{~m}$} & \multirow[b]{3}{*}{ Delta } & \multirow[b]{3}{*}{ P value } \\
\hline & & Epochs & & & Epochs & & & & \\
\hline & & N. & Mean & S.D. & N. & Mean & S.D. & & \\
\hline & C.S & 7 & 73.06 & 6.25 & 35 & 76.73 & 10.05 & 3.67 & n.s. \\
\hline & M.R. & 3 & 84.59 & 7.07 & 3 & 84.66 & 5.94 & 0.07 & n.s. \\
\hline & G.M. & 13 & 83.32 & 5.09 & 12 & 60.03 & 18.26 & -23.29 & 0.0001 \\
\hline & D.C. & 140 & 68.01 & 19.23 & 157 & 74.99 & 17.52 & 6.98 & 0.001 \\
\hline & S.S. & 27 & 58.06 & 13.16 & 64 & 82.43 & 13.95 & 24.37 & 0.0001 \\
\hline & & 190 & & & 271 & & & & \\
\hline & & No. of subjects & Mean & $\begin{array}{c}\text { S.E.M. } \\
\text { subjects }\end{array}$ & No. of subjects & Mean & $\begin{array}{c}\text { S.E.M. } \\
\text { subjects }\end{array}$ & Delta & \\
\hline & Average & 5 & 73.41 & 10.15 & 5 & 75.77 & 13.14 & 2.36 & n.s. \\
\hline \multirow[t]{10}{*}{$S 1+S 2$} & & Epochs & & & Epochs & & & & \\
\hline & & N. & Mean & S.D. & N. & Mean & S.D. & Delta & P value \\
\hline & C.S & 45 & 66.77 & 15.70 & 34 & 65.03 & 15.11 & -1.73 & n.s. \\
\hline & M.R. & 58 & 76.41 & 9.45 & 52 & 80.71 & 6.77 & 4.30 & 0.01 \\
\hline & G.M. & 53 & 78.55 & 7.91 & 54 & 74.44 & 9.50 & -4.11 & 0.0168 \\
\hline & D.C. & 302 & 55.86 & 16.23 & 322 & 80.61 & 9.95 & 24.75 & 0.0001 \\
\hline & S.S. & 200 & 57.67 & 17.92 & 237 & 80.47 & 12.71 & 22.80 & 0.0001 \\
\hline & No. of epochs & 658 & & & & & & & \\
\hline & & No. of subjects & Mean & $\begin{array}{c}\text { S.E.M. } \\
\text { subjects }\end{array}$ & No. of subjects & Mean & $\begin{array}{l}\text { S.E.M. } \\
\text { subjects }\end{array}$ & Delta & \\
\hline & Average & 5 & 67.05 & 13.44 & 5 & 76.25 & 10.81 & -9.2 & n.s. \\
\hline \multirow[t]{10}{*}{$S 3+S 4$} & & Epochs & & & Epochs & & & & \\
\hline & & N. & Mean & S.D. & N. & Mean & S.D. & Delta & $P$ value \\
\hline & C.S & 16 & 47.27 & 11.23 & 9 & 43.27 & 27.23 & -3.85 & n.s. \\
\hline & M.R. & 11 & 63.73 & 12.98 & 6 & 73.90 & 7.93 & 16.10 & 0.015 \\
\hline & G.M. & 9 & 70.19 & 10.08 & 7 & 59.53 & 11.40 & -10.66 & n.s. \\
\hline & D.C. & 98 & 45.84 & 16.91 & 25 & 74.40 & 11.30 & 28.56 & 0.0001 \\
\hline & S.S. & 92 & 39.52 & 16.07 & 59 & 75.93 & 8.95 & 36.41 & 0.0001 \\
\hline & No. of epochs & 226 & & & 106 & & & & \\
\hline & & No. of subjects & Mean & $\begin{array}{l}\text { S.E.M. } \\
\text { subjects }\end{array}$ & No. of subjects & Mean & $\begin{array}{c}\text { S.E.M. } \\
\text { subjects }\end{array}$ & Delta & \\
\hline & Average & 5 & $64.76^{*}$ & 11.45 & 5 & 66.62 & 13.36 & 1.86 & n.s. \\
\hline \multirow[t]{10}{*}{ REM } & & Epochs & & & Epochs & & & & \\
\hline & & N. & Mean & S.D. & N. & Mean & S.D. & Delta & P value \\
\hline & C.S & 8 & 67.97 & 7.94 & 5 & 79.53 & 5.87 & 11.56 & 0.01748 \\
\hline & M.R. & 23 & 80.86 & 5.93 & 13 & 89.00 & 3.82 & 8.14 & 0.0001 \\
\hline & G.M. & 10 & 83.83 & 8.58 & 13 & 79.09 & 7.98 & -4.74 & n.s. \\
\hline & D.C. & 62 & 77.74 & 12.39 & 30 & 87.54 & 6.38 & 9.80 & 0.0001 \\
\hline & S.S. & 72 & 61.18 & 16.03 & 52 & 69.67 & 17.22 & 8.49 & 0.0056 \\
\hline & No. of epochs & 175 & & & 113 & & & & \\
\hline & & No. of subjects & Mean & $\begin{array}{c}\text { S.E.M. } \\
\text { subjects }\end{array}$ & No. of subjects & Mean & $\begin{array}{c}\text { S.E.M. } \\
\text { subjects }\end{array}$ & Delta & \\
\hline & Average & 5 & $74.32^{* *}$ & 10.17 & 5 & 80.97 & 8.25 & 6.65 & n.s. \\
\hline
\end{tabular}

Footnotes to Table 4: ${ }^{(1)}$ One-way ANOVA revealed significant differences in the averages of the total power in low frequency $(0.04-0.15 \mathrm{~Hz})$ in normalized units $\left(\mathrm{LF}_{\mathrm{RR}} \mathrm{NU}\right)(\mathrm{DF} 7,32,39 ; \mathrm{F}=3,229 ; \mathrm{P}<0.0105)$. Post-hoc analysis with Fisher and Scheffe tests revealed that the LF-RR-NU component of the R-R intervals during the $\mathrm{W}$ state at $122 \mathrm{~m}$ differed significantly from than that during stages $\mathrm{S} 3+\mathrm{S} 4(\mathrm{P}=0.05)$. The $\mathrm{LF}$-RR_NU average values during the $\mathrm{W}$ state at $3480 \mathrm{~m}$ differed significantly from that during stages $\mathrm{S} 3+\mathrm{S} 4(\mathrm{P}<0.05)$. The LF-RR-NU average during stages $\mathrm{S} 1+\mathrm{S} 2$ at $122 \mathrm{~m}$ differed significantly from that during REM sleep at $3480 \mathrm{~m}(\mathrm{P}<0.05)$. The LF-RR-NU average during stages $\mathrm{S} 1+\mathrm{S} 2$ recorded at $3480 \mathrm{~m}$ differed significantly from that during stages $\mathrm{S} 3+\mathrm{S} 4$. The LF-RR_NU average during stages S3 + S4 at $122 \mathrm{~m}$ differed significantly from that during REM sleep at $122 \mathrm{~m}(\mathrm{P}<0.05)$. The LF-pR-NU component of the R-R intervals during stages $\mathrm{S} 3+\mathrm{S} 4$ at $122 \mathrm{~m}$ differed significantly from that during REM sleep at $3480 \mathrm{~m}(\mathrm{P}<0.05)$. The LF- ${ }_{\mathrm{RR}}-\mathrm{NU}$ average during stages $\mathrm{S} 3+\mathrm{S} 4$ at $3480 \mathrm{~m}$ differed from that during REM sleep at $3480 \mathrm{~m}(\mathrm{P}<0.05)$ in all five subjects. *Comparison with Student's t-test showed a significant difference between the average of the LF-RR-NU recorded in 19030 -second epochs during the waking period during sleep $(\mathrm{W})$ at $122 \mathrm{~m}(\mathrm{P}<0.03)$ and that recorded in 22630 -second epochs during stages S3 + S4 of NREM sleep at $122 \mathrm{~m}$ in all five subjects. ${ }^{* *}$ Comparison with Student's t-test showed a significant difference (P $<0.0192$ ) between the average of the LF-RR-NU in stages S3 + S4 of NREM sleep and that during REM sleep at $122 \mathrm{~m}$ in all five subjects. 


\subsubsection{Sea Level (122 $\mathrm{m})$ and High Altitude ( $3480 \mathrm{~m})$}

The average $\mathrm{LF}_{\mathrm{RR}} \mathrm{NU}$ (Table 4) recorded during $\mathrm{W}$ at altitude was significantly shorter than that recorded at sea level in $1 / 5$ subjects (GM: $60.03 \pm 18.26$ at $3480 \mathrm{~m}$ vs $83.32 \pm 5.09$ at $122 \mathrm{~m} ; \mathrm{P}<0.0001)$ and significantly longer in $2 / 5$ subjects [(DC: $74.99 \pm 17.52$ at $3480 \mathrm{~m}$ vs $68.01 \pm 19.23$ at $122 \mathrm{~m} ; \mathrm{P}<0.001)$; (SS: $82.43 \pm 13.95$ at $3480 \mathrm{~m}$ vs $58.06 \pm 13.16$ at $122 \mathrm{~m} ; \mathrm{P}<0.0001)]$.

The average $\mathrm{LF}_{\mathrm{RR}} \mathrm{NU}$ recorded during $\mathrm{S} 1+\mathrm{S} 2$ at high altitude was significantly longer than that recorded at sea level in $3 / 5$ subjects [(MR: $80.71 \pm 6.77$ at $3480 \mathrm{~m}$ vs $76.41 \pm 9.45$ at $122 \mathrm{~m}$; $<<0.01$ ); (DC: $80.61 \pm 9.95$ at $3480 \mathrm{~m}$ vs $55.86 \pm 16.23$ at $122 \mathrm{~m}$; $\mathrm{P}<0.0001$ ); (SS: $80.47 \pm 12.71$ at $3480 \mathrm{~m}$ vs $57.67 \pm 17.92$ at $122 \mathrm{~m} ; \mathrm{P}<$ $0.0001)$ ], while in $1 / 5$ the average $L_{R R} N U$ was significantly shorter (GM: $59.53 \pm 11.40$ at $3480 \mathrm{~m}$ vs $70.19 \pm$ 10.08 at $122 \mathrm{~m} ; \mathrm{P}<0.0168)$ in $\mathrm{S} 3+\mathrm{S} 4$. The average $\mathrm{LF}_{\mathrm{RR}} \mathrm{NU}$ recorded during $\mathrm{S} 3+\mathrm{S} 4$ at high altitude was significantly longer than that recorded at $122 \mathrm{~m}$ in $3 / 5$ subjects [(MR: $73.90 \pm 7.93$ at $3480 \mathrm{~m}$ vs $63.73 \pm 12.98$ at $122 \mathrm{~m} ; \mathrm{P}<0.0150$ ); (DC: $74.40 \pm 11.30$ at $3480 \mathrm{~m}$ vs $45.84 \pm 16.91$ at $122 \mathrm{~m} ; \mathrm{P}<0.0001)$; (SS: $75.93 \pm 8.95$ at $3480 \mathrm{~m}$ vs $39.52 \pm 16.07$ at $122 \mathrm{~m} ; \mathrm{P}<0.0001)]$. The average $\mathrm{LF}_{\mathrm{RR}} \mathrm{NU}$ recorded during REM sleep at high altitude was significantly longer than that recorded at 122 $\mathrm{m}$ in $4 / 5$ subjects [(CS: $79.53 \pm 5.87$ at $3480 \mathrm{~m}$ vs 67.97 \pm 7.94 at $122 \mathrm{~m} ; \mathrm{P}<0.01748$ ); (MR: $89.00 \pm 3.82$ at $3480 \mathrm{~m}$ vs $80.86 \pm 5.93$ at $122 \mathrm{~m}$; $\mathrm{P}<0.0001$ ); (DC: $87.54 \pm 6.38$ at $3480 \mathrm{~m}$ vs $77.74 \pm 12.39$ at $122 \mathrm{~m} ; \mathrm{P}<$ 0.0001 ); (SS: $69.67 \pm 17.22$ at $3480 \mathrm{~m}$ vs $61.18 \pm 16.03$ at $122 \mathrm{~m} ; \mathrm{P}<0.0056)]$. These data show a great variability between mountain marathon runners in $\mathrm{LF}_{\mathrm{RR}} \mathrm{NU}$ when the data set recorded at $122 \mathrm{~m}$ is compared with that recorded at $3480 \mathrm{~m}$. Analysis of the data recorded in individual mountain marathon runners showed an increase in the average $\mathrm{LF}_{\mathrm{RR}} \mathrm{NU}$ at $3480 \mathrm{~m}$, demonstrating an increase in the marker for sympathetic modulation.

\subsection{Total Power of High Frequency [(HF, $\left.\mathrm{ms}^{2}\right)$ (0.15 - 0.4 Hz)] Range. HF Primarily Reflects Respiratory-Driven Vagal Modulation of Sinus Rhythm}

\subsubsection{Sea Level (122 m)}

No significant differences in the averages of HF were observed between W (2223 \pm 728$), \mathrm{S} 1+\mathrm{S} 2(2945 \pm$ $1080)$ and S3 + S4 (3891 \pm 1134$)$ and REM (2499 \pm 879$)$ stages at low altitude (Table 5). The averages of the HF recorded during the nocturnal sleep-wake cycle at $122 \mathrm{~m}$ suggested a prevalence of vagal tone during $\mathrm{S} 3+\mathrm{S} 4$ stages in comparison with the other sleep stages.

\subsubsection{High Altitude ( $3480 \mathrm{~m})$}

No significant differences in the averages of HF were observed between W (1572 \pm 993$), \mathrm{S} 1+\mathrm{S} 2$ (1610 \pm 631$)$ and S3 + S4 (1480 \pm 511$)$ and REM (1159 \pm 555$)$ stages at $3480 \mathrm{~m}$ (Table 5). The averages of the HF recorded during the nocturnal sleep-wake cycle at $3480 \mathrm{~m}$ suggested a reduction in vagal tone throughout all sleep stages and during awakening during sleep.

\subsubsection{Sea Level (122 $\mathrm{m})$ and High Altitude ( $3480 \mathrm{~m})$}

Compared with the values calculated at sea level, there was a significant decrease in the average of total power of high frequency (HF, $\mathrm{ms}^{2}$ ) (Table 5) recorded during $\mathrm{W}$ at altitude in $3 / 5$ subjects [(CS: $1422 \pm 384$ at $122 \mathrm{~m}$ vs $743 \pm 191$ at $3480 \mathrm{~m} ; \mathrm{P}<0.0001$ ); (DC: $1487 \pm 729$ at $122 \mathrm{~m}$ vs $717 \pm 789$ at $3480 \mathrm{~m} ; \mathrm{P}<0.0001)$; (SS: $4849 \pm$ 1587 at $122 \mathrm{~m}$ vs $1674 \pm 1179$ at $3480 \mathrm{~m} ; \mathrm{P}<0.0001)$ ] and a significant increase in 1/5 subjects (GM: $1654 \pm$ 400 at $122 \mathrm{~m}$ vs $3495 \pm 2196$ at $3480 \mathrm{~m} ; \mathrm{P}<0.0072$ ).

Compared with the values calculated at sea level, there was a significant decrease in the average $\mathrm{HF}$ recorded at altitude during S1 + S2 of NREM sleep in $4 / 5$ subjects [(CS: $2485 \pm 1178$ at $122 \mathrm{~m}$ vs $1513 \pm 443$ at $3480 \mathrm{~m}$; P $<0.0001$ ); (MR: $2892 \pm 906$ at $122 \mathrm{~m}$ vs $1382 \pm 546$ at $3480 \mathrm{~m}$; $\mathrm{P}<0.0001$ ); (DC: $2167 \pm 778$ at $122 \mathrm{~m}$ vs $605 \pm$ 297 at $3480 \mathrm{~m} ; \mathrm{P}<0.0001$ ); (SS: $5375 \pm 1950$ at $122 \mathrm{~m}$ vs $2640 \pm 1385$ at $3480 \mathrm{~m} ; \mathrm{P}<0.0001)]$. Compared with the averages calculated at $122 \mathrm{~m}$, there was a significant decrease in the average HF recorded during $\mathrm{S} 3+\mathrm{S} 4$ of NREM sleep at $3480 \mathrm{~m}$ in $4 / 5$ subjects [(CS: $3776 \pm 982$ at $122 \mathrm{~m}$ vs $2044 \pm 723$ at $3480 \mathrm{~m} ; \mathrm{P}<0.0001$ ); (MR: $4624 \pm 1629$ at $122 \mathrm{~m}$ vs $975 \pm 506$ at $3480 \mathrm{~m} ; \mathrm{P}<$ 0.0001); (DC: $2617 \pm 777$ at $122 \mathrm{~m}$ vs $684 \pm 249$ at 3480 m; P < 0.0001); (SS: 6,866 \pm 1904 at $122 \mathrm{~m}$ vs $1394 \pm$ 681 at $3480 \mathrm{~m} ; \mathrm{P}<0.0001)]$ and a significant increase in $1 / 5$ subjects (GM: $1571 \pm 376$ at $122 \mathrm{~m}$ vs $2303 \pm 396$ at $3480 \mathrm{~m} ; \mathrm{P}<0.0021)$. There was a significant decrease in the average HF recorded during REM sleep in 4/5 subjects [(CS: $2425 \pm 531$ at $122 \mathrm{~m}$ vs $1397 \pm 774$ at $3480 \mathrm{~m}$; $\mathrm{P}<0.0155$ ); (MR: $2248 \pm 680$ at $122 \mathrm{~m}$ vs $615 \pm 233$ at $3480 \mathrm{~m} ; \mathrm{P}<0.0001)$; (DC: $1530 \pm 708$ at $122 \mathrm{~m}$ vs $400 \pm$ 149 at $3480 \mathrm{~m}$; $\mathrm{P}<0.0001$ ); (SS: $4885 \pm 1559$ at $122 \mathrm{~m}$ vs $1671 \pm 1147$ at $3480 \mathrm{~m} ; \mathrm{P}<0.0001)]$.

The average $\mathrm{HF}$ at $3480 \mathrm{~m}$ recorded in individual mountain marathon runners was generally lower than that recorded at $122 \mathrm{~m}$, suggesting a decrease in the marker of vagal tone at altitude.

\subsection{High Frequency in Normalized Units $\left[\left(\mathrm{HF}_{\mathrm{RR}} \mathrm{NU}\right)(0.04-0.15 \mathrm{~Hz})\right] . \mathrm{HF}_{\mathrm{RR}} \mathrm{NU}$ Is Considered as a Marker of Vagal Modulation}

3.6.1. Sea Level (122 m)

In all five subjects, the average of the $\mathrm{HF}_{\mathrm{RR}} \mathrm{NU}$ analyzed 
Table 5. Averages of the total power in the high frequency $\left(\mathrm{HF}, \mathrm{ms}^{2}\right)(0.15-0.4 \mathrm{~Hz})$ range, which primarily reflects respiratory-driven vagal modulation of sinus rhythm, in a natural, physiologically defined number of 30-second signal epochs, according to the standard criteria developed by Rechtschaffen and Kales (1968), during the waking period during sleep (W), stages S1 + S2 and S3 + S4 of NREM and REM sleep measured at $122 \mathrm{~m}$ and after $30-41 \mathrm{~h}$ of acclimatisation at $3480 \mathrm{~m}$ in the five subjects. ${ }^{(1)}$

\begin{tabular}{|c|c|c|c|c|c|c|c|c|c|}
\hline \multirow[b]{3}{*}{ Awakening during sleep } & \multirow[t]{2}{*}{ Subjects } & \multicolumn{3}{|c|}{$122 \mathrm{~m}$} & \multicolumn{3}{|c|}{$3480 \mathrm{~m}$} & \multirow[b]{3}{*}{ Delta } & \multirow[b]{3}{*}{$P$ value } \\
\hline & & Epochs & & & Epochs & & & & \\
\hline & & N. & Mean & S.D. & N. & Mean & S.D. & & \\
\hline & C.S & 7 & 1422 & 384 & 35 & 743 & 191 & -679 & 0.0001 \\
\hline & M.R. & 3 & 1701 & 449 & 3 & 1232 & 612 & -469 & n.s. \\
\hline & G.M. & 13 & 1654 & 490 & 12 & 3495 & 2196 & 1841 & 0.0072 \\
\hline & D.C. & 140 & 1487 & 729 & 157 & 717 & 789 & -770 & 0.0001 \\
\hline & S.S. & 27 & 4849 & 1587 & 64 & 1674 & 1179 & -3175 & 0.0001 \\
\hline & No. of epochs & 190 & & & 271 & & & & \\
\hline & & No. of subjects & Mean & $\begin{array}{c}\text { S.E.M. } \\
\text { subjects }\end{array}$ & No. of subjects & Mean & $\begin{array}{c}\text { S.E.M. } \\
\text { subjects }\end{array}$ & Delta & \\
\hline & Average & 5 & 2223 & 728 & 5 & 1572 & 993 & -651 & n.s. \\
\hline \multirow[t]{10}{*}{$S 1+S 2$} & & Epochs & & & Epochs & & & & \\
\hline & & N. & Mean & S.D. & N. & Mean & S.D. & Delta & $P$ value \\
\hline & C.S & 45 & 2485 & 1178 & 34 & 1513 & 443 & -972 & 0.0001 \\
\hline & M.R. & 58 & 2892 & 906 & 52 & 1382 & 546 & -1510 & 0.0001 \\
\hline & G.M. & 53 & 1807 & 589 & 54 & 1909 & 484 & 102 & n.s. \\
\hline & D.C. & 302 & 2167 & 778 & 322 & 605 & 297 & -1562 & 0.0001 \\
\hline & S.S. & 200 & 5375 & 1950 & 237 & 2640 & 1385 & -2735 & 0.0001 \\
\hline & No. of epochs & 658 & & & 699 & & & & \\
\hline & & No. of subjects & Mean & $\begin{array}{c}\text { S.E.M. } \\
\text { subjects }\end{array}$ & No. of subjects & Mean & $\begin{array}{l}\text { S.E.M. } \\
\text { subjects }\end{array}$ & Delta & \\
\hline & Average & 5 & 2945 & 1080 & 5 & 1610 & 631 & 1335 & n.s. \\
\hline \multirow[t]{10}{*}{$S 3+S 4$} & & Epochs & & & Epochs & & & & \\
\hline & & N. & Mean & S.D. & N. & Mean & S.D. & Delta & $P$ value \\
\hline & C.S & 16 & 3776 & 982 & 9 & 2044 & 723 & -1732 & 0.0001 \\
\hline & M.R. & 11 & 4624 & 1629 & 6 & 975 & 506 & -3649 & 0.0001 \\
\hline & G.M. & 9 & 1571 & 376 & 7 & 2303 & 396 & 732 & 0.0021 \\
\hline & D.C. & 98 & 2617 & 777 & 25 & 684 & 249 & -1933 & 0.0001 \\
\hline & S.S. & 92 & 6866 & 1904 & 59 & 1394 & 681 & -5472 & 0.0001 \\
\hline & No. of epochs & 226 & & & 106 & & & & \\
\hline & & No. of subjects & Mean & $\begin{array}{c}\text { S.E.M. } \\
\text { subjects }\end{array}$ & No. of subjects & Mean & $\begin{array}{l}\text { S.E.M. } \\
\text { subjects }\end{array}$ & Delta & \\
\hline & Average & 5 & 3891 & 1134 & 5 & 1480 & 511 & -2411 & 0.04 \\
\hline \multirow[t]{10}{*}{ REM } & & Epochs & & & Epochs & & & & \\
\hline & & N. & Mean & S.D. & N. & Mean & S.D. & Delta & $P$ value \\
\hline & C.S & 8 & 2425 & 531 & 5 & 1397 & 774 & -1028 & 0.0155 \\
\hline & M.R. & 23 & 2248 & 680 & 13 & 615 & 233 & -1633 & 0.0001 \\
\hline & G.M. & 10 & 1409 & 918 & 13 & 1711 & 472 & 302 & n.s. \\
\hline & D.C. & 62 & 1530 & 708 & 30 & 400 & 149 & -1130 & 0.0001 \\
\hline & S.S. & 72 & 4885 & 1559 & 52 & 1671 & 1147 & -1147 & 0.0001 \\
\hline & No. of epochs & 175 & & & 113 & & & & \\
\hline & & No. of subjects & Mean & $\begin{array}{c}\text { S.E.M. } \\
\text { subjects }\end{array}$ & No. of subjects & Mean & $\begin{array}{l}\text { S.E.M. } \\
\text { subjects }\end{array}$ & Delta & \\
\hline & Average & 5 & 2499 & 879 & 5 & 1159 & 555 & -1340 & n.s. \\
\hline
\end{tabular}

Footnotes to Table 5: ${ }^{(1)}$ One-way ANOVA revealed a significant difference between stages in the averages of the total power in the high frequency (HF, ms ${ }^{2}$ ) $(0.15-0.4 \mathrm{~Hz})$ range $\left(\mathrm{DF}=7_{32,39} ; \mathrm{F}=2,576, \mathrm{P}=0,0317\right)$. Post-hoc Fisher analysis showed significant differences between the averages of $\mathrm{HF}$ during $\mathrm{W}$ at 122 $\mathrm{m}$ and during stages $\mathrm{S} 3+\mathrm{S} 4$ at $122 \mathrm{~m}(\mathrm{P}<0.05)$. There was a significant difference between the values measured during $\mathrm{W}$ at $3480 \mathrm{~m}$ and those during stages $\mathrm{S} 3+\mathrm{S} 4$ at $122 \mathrm{~m}(\mathrm{P}<0.05)$. The values measured during stages $\mathrm{S} 1+\mathrm{S} 2$ at $122 \mathrm{~m}$ differed significantly from those during REM sleep at $3480 \mathrm{~m}$ in all five subjects. 
in a natural, physiologically defined number of 30 -second signal epochs, according to standard criteria developed by Rechtschaffen and Kales (1968), during the awakening period during sleep (W: $23.47 \pm 9.46$ ) was significantly shorter than that observed during S3 + S4 of NREM at $122 \mathrm{~m}(56.91 \pm 31.14 ; \mathrm{P}<0.0327)$. In all five subjects, the average of the $\mathrm{HF}_{\mathrm{RR}} \mathrm{NU}$ during $\mathrm{S} 3+\mathrm{S} 4$ of NREM sleep $(56.91 \pm 31.14)$ was significantly longer ( $P$ $<0.01004)$ than that observed during REM sleep (22.64 $\pm 9.44 ; \mathrm{P}<0.01004)$ at $122 \mathrm{~m}$ (Table 6). These data suggest an increase in vagal modulation during the deepening of slow-wave NREM sleep and a decrease in vagal modulation during the desynchronized awakening period during sleep (W) and REM sleep.

\subsubsection{High Altitude ( $3480 \mathrm{~m})$}

The average of the $\mathrm{HF}_{\mathrm{RR}} \mathrm{NU}$ analyzed between $\mathrm{W}(21.31$ $\pm 11.08), \mathrm{S} 1+\mathrm{S} 2$ (21.52 \pm 9.76$), \mathrm{S} 3+\mathrm{S} 4(31.11 \pm 12.81)$ of NREM sleep and REM sleep (16.74 \pm 6.99$)$ was similar (Table 6). The data suggest an increase in vagal modulation during S3 + S4 of slow-wave NREM sleep and a decrease in vagal modulation during the desynchronized awakening period during sleep (W), S1 + S2 of NREM sleep and during REM sleep.

\subsubsection{Sea Level $(122 \mathrm{~m})$ and High Altitude $(3480 \mathrm{~m})$}

The mean of the averages of the $\mathrm{HF}_{\mathrm{RR}} \mathrm{NU}$ (Table 6) recorded during $\mathrm{W}$ at altitude was significantly shorter than that recorded at sea level in 2/5 subjects (DC: $22.29 \pm$ 14.47 at $3480 \mathrm{~m}$ vs $30.87 \pm 18.75$ at $122 \mathrm{~m} ; \mathrm{P}<0.0001$ ); (SS: $15.33 \pm 11.65$ at $3480 \mathrm{~m}$ vs $33.49 \pm 11.57$ at $122 \mathrm{~m}$; $\mathrm{P}<0.0001)$ ] and significantly longer in $1 / 5$ subjects (GM: $33.15 \pm 13.39$ at $3480 \mathrm{~m}$ vs $15.15 \pm 4.6$ at $122 \mathrm{~m} ; \mathrm{P}<$ $0.0001)$. The mean of the averages of the $\mathrm{HF}_{\mathrm{RR}} \mathrm{NU}$ recorded during $\mathrm{S} 1+\mathrm{S} 2$ at altitude was significantly shorter than that recorded at sea level in $3 / 5$ subjects (MR: $18.81 \pm 6.71$ at $3480 \mathrm{~m}$ vs $23.17 \pm 9.48$ at $122 \mathrm{~m} ; \mathrm{P}<$ 0.01 ); (DC: $18.32 \pm 9.43$ at $3480 \mathrm{~m}$ vs $43.57 \pm 16.23$ at $122 \mathrm{~m} ; \mathrm{P}<0.001$ ); (SS: $16.38 \pm 10.36$ at $3480 \mathrm{~m}$ vs $36.86 \pm 17.23$ at $122 \mathrm{~m} ; \mathrm{P}<0.0001)$. The mean of the averages of the $\mathrm{HF}_{\mathrm{RR}}-\mathrm{NU}$ recorded during $\mathrm{S} 3+\mathrm{S} 4$ at altitude was significantly shorter than that recorded at sea level in 2/5 subjects [(DC: $24.42 \pm 11.04$ at $3480 \mathrm{~m}$ vs $53.53 \pm 16.73$ at $122 \mathrm{~m} ; \mathrm{P}<0.0001$ ); (SS: $22.29 \pm 8.30$ at $3480 \mathrm{~m}$ vs $55.54 \pm 15.78$ at $122 \mathrm{~m} ; \mathrm{P}<0.0001)]$. The mean of the averages of the $\mathrm{HF}_{\mathrm{RR}}-\mathrm{NU}$ recorded during REM sleep at altitude was significantly shorter than that at sea level in $3 / 5$ subjects [(MR: $10.57 \pm 3.76$ at $3480 \mathrm{~m}$ vs $18.50 \pm 5.82$ at $122 \mathrm{~m}: \mathrm{P}<0.0001$ ); (DC: $11.56 \pm 6.14$ at $3480 \mathrm{~m}$ vs $21.80 \pm 12.24$ at $122 \mathrm{~m}$; $\mathrm{P}<0.0001$ ); (SS: $26.81 \pm 14.55$ at $3480 \mathrm{~m}$ vs $32.15 \pm 14.57$ at $122 \mathrm{~m} ; \mathrm{P}<$ $0.04)]$.

\subsection{LF:HF Ratio Mirrors Sympathovagal Balance or Reflects Sympathetic Modulation}

\subsubsection{Sea Level (122 m)}

In all five subjects, the average of the LF:HF ratio during $\mathrm{W}$ at $122 \mathrm{~m}$ was longer $(4.6446 \pm 2.8655)$ than that observed during S3 + S4 $(1.6733 \pm 1.0847 ; \mathrm{P}<0.0110)$ (Table 7); the average of the LF:HF ratio during S3+S4 $(1.6733 \pm 1.0847)$ was significantly shorter than that observed in 175 epochs of REM sleep (4.4739 \pm 2.1405 ; P $<0.0113$ ) (Table 7). The data suggest an increase of sympathetic modulation during $\mathrm{W}$ and REM sleep in comparison of synchronized S1 - S4 sleep.

\subsubsection{High Altitude $(3480 \mathrm{~m})$}

The average of the LF:HF ratio during S3 $+\mathrm{S} 4$ at $3480 \mathrm{~m}$ $(3.2109 \pm 1.0873)$ was significantly lower than that observed during REM sleep $(6.9132 \pm 3.6806 ; \mathrm{P}<$ 0.036835 ). The data suggest an increase of sympathetic modulation during REM sleep in comparison to synchronized S3 + S4 sleep.

\subsubsection{Sea Level ( $122 \mathrm{~m})$ and High Altitude $(3480 \mathrm{~m})$}

The average of the LF:HF ratio (Table 7) during $\mathrm{W}$ was significantly shorter at $3480 \mathrm{~m}$ than at $122 \mathrm{~m}$ in $1 / 5 \mathrm{sub}-$ jects (GM: $6.1615 \pm 2.4214$ at $122 \mathrm{~m}$ vs $2.3017 \pm 1.3728$ at $3480 \mathrm{~m} ; \mathrm{P}<0.0001)$ and significantly longer at 3480 $\mathrm{m}$ than at $122 \mathrm{~m}$ in $2 / 5$ subjects [(DC: $4.9300 \pm 6.2275$ at $122 \mathrm{~m}$ vs $7.2334 \pm 10.049$ at $3480 \mathrm{~m}$; $\mathrm{P}<0.0235$ ); (SS: $2.1570 \pm 1.4672$ at $122 \mathrm{~m}$ vs $9.4181 \pm 8.1271$ at $3480 \mathrm{~m}$; $\mathrm{P}<0.0001)$ ]. The average LF:HF ratio during $\mathrm{S} 1+\mathrm{S} 2$ was significantly longer at $3480 \mathrm{~m}$ than at $122 \mathrm{~m}$ in $3 / 5$ subjects [(MR: $5.0512 \pm 2.3613$ at $3480 \mathrm{~m}$ vs $3.9624 \pm$ 1.8413 at $122 \mathrm{~m}$; $\mathrm{P}<0.0078$ ); (DC: $6.1907 \pm 4.3641$ at $3480 \mathrm{~m}$ vs $1.7193 \pm 1.3779$ at $122 \mathrm{~m} ; \mathrm{P}<0.0001$ ); (SS: $7.9224 \pm 6.7405$ at $3480 \mathrm{~m}$ vs $2.3667 \pm 2.16997$ at $122 \mathrm{~m}$; $\mathrm{P}<0.0001)$ ] and significantly shorter in $1 / 5$ subjects (GM: $3.9050 \pm 1.6255$ at $3480 \mathrm{~m}$ vs $4.6160 \pm 2.0671$ at $122 \mathrm{~m} ; \mathrm{P}<0.0503)$. The average LF:HF ratio was significantly longer at high altitude than at sea level during $\mathrm{S} 3+\mathrm{S} 4$ in $3 / 5$ subjects [(MR: $4.6867 \pm 1.8516$ at $3480 \mathrm{~m}$ vs $2.1655 \pm 1.2576$ at $122 \mathrm{~m} ; \mathrm{P}<0.0043$ ); (DC: $3.7484 \pm$ 1.7785 at $3480 \mathrm{~m}$ vs $1.2203 \pm 1.4342$ at $122 \mathrm{~m} ; \mathrm{P}<$ 0.0001 ); (SS: $4.0205 \pm 2.3448$ at $3480 \mathrm{~m}$ vs $0.9542 \pm$ 1.0418 at $122 \mathrm{~m} ; \mathrm{P}<0.0001)]$. The average LF:HF ratio was significantly longer $(\mathrm{P}<0.0102-0.0001)$ during REM sleep at high altitude than at sea level in $4 / 5$ subjects [(CS: $4.7380 \pm 1.4928$ at $3480 \mathrm{~m}$ vs $2.8163 \pm$ 0.9832 at $122 \mathrm{~m}$ ); (MR: $9.8554 \pm 4.3032$ at $3480 \mathrm{~m}$ vs $4.8217 \pm 1.5891$ at $122 \mathrm{~m}$ ); (DC: $10.520 \pm 6.6211$ at $3480 \mathrm{~m}$ vs $5.2563 \pm 3.7020$ at $122 \mathrm{~m}$ ); (SS: $4.1387 \pm$ 3.9490 at $3480 \mathrm{~m}$ vs $2.7194 \pm 2.0375$ at $122 \mathrm{~m}$ )].

At $122 \mathrm{~m}$ and at $3480 \mathrm{~m}$ there was a decrease in the LF:HF ratio during deepening of NREM sleep, indicating 
Table 6. Averages of the total power in the high frequency $(0.04-0.15 \mathrm{~Hz})$ range in normalized units $\left(\mathrm{HF} \mathrm{RR}_{\mathrm{NU}} \mathrm{NU}\right.$, which is considered as a marker of vagal modulation, in a natural, physiologically defined number of 30-second signal epochs, according to standard criteria developed by Rechtschaffen and Kales (1968), during the waking period during sleep (W), stages $\mathrm{S} 1+\mathrm{S} 2$ and $\mathrm{S3}+\mathrm{S} 4 \mathrm{of}$ NREM and REM sleep recorded at $122 \mathrm{~m}$ and after $30-41 \mathrm{~h}$ of acclimatisation at $3480 \mathrm{~m}$ in the five subjects. $^{(1)}$

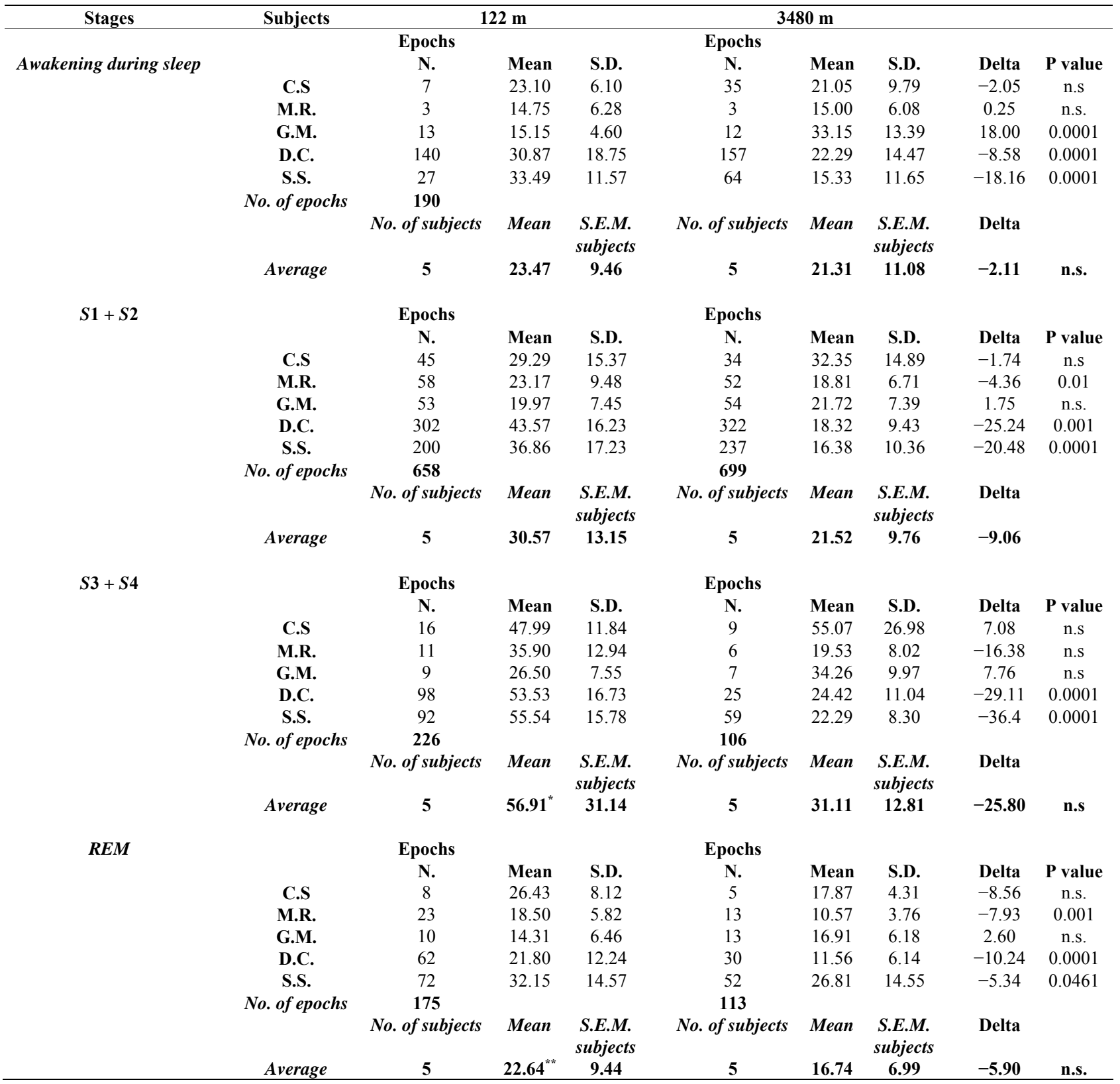

Footnotes to Table 6: ${ }^{(1)}$ One-way ANOVA of the averages of the total power in the high frequency $(0.04-0.15 \mathrm{~Hz})$ range in normalized units $(\mathrm{HF}-\mathrm{RR}$-NU) showed significant differences between conditions (DF7,32,39; F 4071; P $<0.0027$ ). Post-hoc analysis demonstrated a significant difference between the average HF-RR-NU during $\mathrm{W}$ at $122 \mathrm{~m}$ and that during stages $\mathrm{S} 3+\mathrm{S} 4$ at $122 \mathrm{~m}(\mathrm{P}<0.05)$. The averages of $\mathrm{HF}-\mathrm{RR}_{-\mathrm{NU}}$ during $\mathrm{W}$ at $3480 \mathrm{~m}$ differed significantly from those during stages $\mathrm{S} 3+\mathrm{S} 4$ at $122(\mathrm{P}<0.05)$. The averages of HF-RR-NU during W at $122 \mathrm{~m}$ differed significantly from those during stages $\mathrm{S} 3+\mathrm{S} 4$ at $122 \mathrm{~m}$ $(\mathrm{P}<0.05)$. The average of $\mathrm{HF}-\mathrm{RR}-\mathrm{NU}$ during stages $\mathrm{S} 1+\mathrm{S} 2$ at $122 \mathrm{~m}$ differed significantly from that during stages $\mathrm{S} 3+\mathrm{S} 4$ at $3480 \mathrm{~m}(\mathrm{P}<0.05)$. The average of HF-RR-NU during stages S1 + S2 at $3480 \mathrm{~m}$ differed significantly from that during stages S3 $+\mathrm{S} 4$ at $122 \mathrm{~m}(\mathrm{P}<0.05)$. The average of HF-RR-NU during stages S3 + S4 at $122 \mathrm{~m}$ differed significantly from that during stages S3 $+\mathrm{S} 4$ at $3480 \mathrm{~m}(\mathrm{P}<0.05)$. The average of $\mathrm{HF}-\mathrm{RR}-\mathrm{NU}$ during stages $\mathrm{S} 3+\mathrm{S} 4$ at $122 \mathrm{~m}$ differed significantly from that during REM sleep at $122 \mathrm{~m}(\mathrm{P}<0.05)$; The average of $\mathrm{HF}-\mathrm{RR}-\mathrm{NU}$ during stages $\mathrm{S} 3+\mathrm{S} 4$ at $122 \mathrm{~m}$ differed significantly from that during stages $\mathrm{S} 3+\mathrm{S} 4$ at $3480 \mathrm{~m}(\mathrm{P}<0.05)$; The average of $\mathrm{HF}_{-\mathrm{RR}}-\mathrm{NU}$ during stages $\mathrm{S} 3+\mathrm{S} 4$ at $3480 \mathrm{~m}$ differed significantly from that during REM sleep at $3480 \mathrm{~m}(\mathrm{P}<0.05)$ in all five subjects. "Comparison with Student's t-test of the average of the HF-RR-NU, in a natural, physiologically defined number of 30-second signal epochs, according to standard criteria developed by Rechtschaffen and Kales (1968), during the waking period during sleep (W) differed significantly from that during stages S3 + S4 of NREM sleep at $122 \mathrm{~m}$ in all five subjects $(\mathrm{P}<0.0327)$. ${ }^{* *}$ Comparison with Student's t-test of the average of the $\mathrm{HF}_{-\mathrm{RR}}-\mathrm{NU}$, in a natural, physiologically defined number of 30-second signal epochs, according to standard criteria developed by Rechtschaffen and Kales (1968), during stages S3 + S4 of NREM sleep differed significantly from that during REM sleep at $122 \mathrm{~m}$ in all five subjects (P $<0.01004)$. 
Table 7. Averages of the ratio of low frequency/high frequency $\left(\mathrm{LF}, \mathrm{ms}^{2} / \mathrm{HF}, \mathrm{ms}^{2}\right)$ range, which mirrors sympathovagal balance or reflects sympathetic modulation, in a physiologically defined number of 30-second signal epochs, according to standard criteria developed by Rechtschaffen and Kales (1968), during the waking period during sleep (W), stages S1 + S2 and S3 $+\mathrm{S} 4$ of NREM sleep and REM sleep at $122 \mathrm{~m}$ and after $30-41 \mathrm{~h}$ of acclimatisation at $3480 \mathrm{~m}$ in the five subjects. ${ }^{(1)}$

\begin{tabular}{|c|c|c|c|c|c|c|c|c|c|}
\hline \multirow[t]{2}{*}{ Stages } & \multirow[t]{2}{*}{ Subjects } & \multicolumn{3}{|l|}{$122 \mathrm{~m}$} & \multicolumn{3}{|l|}{$3480 \mathrm{~m}$} & \multirow[b]{3}{*}{ Delta } & \multirow[b]{3}{*}{$P$ value } \\
\hline & & Epochs & & & Epochs & & & & \\
\hline \multirow[t]{9}{*}{ Awakening during sleep } & & N. & Mean & S.D. & N. & Mean & S.D. & & \\
\hline & C.S & 7 & 3.47 & 1.4415 & 35 & 4.5477 & 2.2645 & 1.0777 & n.s. \\
\hline & M.R. & 3 & 6.513 & 2.77 & 3 & 6.517 & 3.324 & 0.004 & n.s. \\
\hline & G.M. & 13 & 6.1615 & 2.4214 & 12 & 2.3017 & 1.3728 & -3.8598 & 0.0001 \\
\hline & D.C. & 140 & 4.93 & 6.2275 & 157 & 7.2334 & 10.049 & 2.3034 & 0.0235 \\
\hline & S.S. & 27 & 2.157 & 1.4672 & 64 & 9.4181 & 8.1271 & 7.2611 & 0.0001 \\
\hline & No. of epochs & 190 & & & 271 & & & & \\
\hline & & No. of subjects & Mean & $\begin{array}{l}\text { S.E.M. } \\
\text { subjects }\end{array}$ & No. of subjects & Mean & $\begin{array}{l}\text { S.E.M. } \\
\text { subjects }\end{array}$ & Delta & \\
\hline & Average & 5 & 4.6446 & 2.8655 & 5 & 6.0036 & 5.0276 & 1.357 & n.s. \\
\hline \multirow[t]{10}{*}{$S 1+S 2$} & & Epochs & & & Epochs & & & & \\
\hline & & N. & Mean & S.D. & N. & Mean & S.D. & Delta & $P$ value \\
\hline & C.S & 45 & 2.9293 & 1.5299 & 34 & 2.5515 & 1.3856 & -0.3778 & n.s. \\
\hline & M.R. & 58 & 3.9624 & 1.8413 & 52 & 5.0512 & 2.3613 & 1.0888 & 0.0078 \\
\hline & G.M. & 53 & 4.616 & 2.0671 & 54 & 3.905 & 1.6255 & -0.711 & 0.0503 \\
\hline & D.C. & 302 & 1.7193 & 1.3779 & 322 & 6.1907 & 4.3641 & 4.4714 & 0.0001 \\
\hline & S.S. & 200 & 2.3667 & 2.1697 & 220 & 7.9224 & 6.7405 & 5.5557 & 0.0001 \\
\hline & No. of epochs & 658 & & & 683 & & & & \\
\hline & & No. of subjects & Mean & $\begin{array}{l}\text { S.E.M. } \\
\text { subjects }\end{array}$ & No. of subjects & Mean & $\begin{array}{l}\text { S.E.M. } \\
\text { subjects }\end{array}$ & Delta & \\
\hline & Average & 5 & 3.1187 & 1.7972 & 5 & 5.1242 & 3.2954 & 2.007 & n.s. \\
\hline \multirow[t]{10}{*}{$S 3+S 4$} & & Epochs & & & Epochs & & & & \\
\hline & & N. & Mean & S.D. & N. & Mean & S.D. & Delta & $P$ value \\
\hline & C.S & 16 & 1.0919 & 0.477 & 9 & 1.6633 & 2.2308 & 0.5714 & n.s. \\
\hline & M.R. & 11 & 2.1655 & 1.2576 & 6 & 4.6867 & 1.8516 & 2.5212 & 0.0043 \\
\hline & G.M. & 9 & 2.9344 & 1.2127 & 7 & 1.9357 & 0.831 & -0.9987 & n.s. \\
\hline & D.C. & 98 & 1.2203 & 1.4342 & 25 & 3.7484 & 1.7785 & 2.5281 & 0.0001 \\
\hline & S.S. & 92 & 0.9542 & 1.0418 & 59 & 4.0205 & 2.3448 & 3.25 & 0.0001 \\
\hline & No. of epochs & 226 & & & & & & & \\
\hline & & No. of subjects & Mean & $\begin{array}{l}\text { S.E.M. } \\
\text { subjects }\end{array}$ & No. of subjects & Mean & $\begin{array}{l}\text { S.E.M. } \\
\text { subjects }\end{array}$ & Delta & \\
\hline & Average & 5 & $1.633^{*}$ & 1.0847 & 5 & 3.2109 & 1.8073 & 1.538 & n.s. \\
\hline \multirow[t]{10}{*}{ REM } & & Epochs & & & Epochs & & & & \\
\hline & & N. & Mean & S.D. & N. & Mean & S.D. & Delta & $P$ value \\
\hline & C.S & 8 & 2.81163 & & 5 & 4.738 & 1.4928 & 1.9217 & 0.0166 \\
\hline & M.R. & 23 & 4.82217 & & 13 & 9.8554 & 4.3032 & 5.0337 & 0.0001 \\
\hline & G.M. & 10 & 6.756 & & 13 & 5.3138 & 2.0368 & -1.4422 & n.s. \\
\hline & D.C. & 62 & 5.2563 & & 30 & 10.52 & 6.6211 & 5.264 & 0.0001 \\
\hline & S.S. & 72 & 2.7194 & & 52 & 4.1387 & 3.949 & 1.493 & 0.0102 \\
\hline & No. of epochs & 175 & & & 113 & & & & \\
\hline & & No. of subjects & Mean & $\begin{array}{l}\text { S.E.M. } \\
\text { subjects }\end{array}$ & No. of subjects & Mean & $\begin{array}{l}\text { S.E.M. } \\
\text { subjects }\end{array}$ & Delta & \\
\hline & Average & 5 & $4.4739^{* *}$ & & 5 & $6.9132^{* * * *}$ & 3.6806 & 2.439 & n.s. \\
\hline
\end{tabular}

Footnotes to Table 7: ${ }^{(1)}$ One-way ANOVA showed no significant differences in the LF/HF ratio in the different conditions. ${ }^{*}$ Student's t-test showed that the average of the total power of the LF/HF ratio during the waking state during sleep (W) (190 epochs) at $122 \mathrm{~m}$ was generally higher than the average LF/HF ratio during stages $\mathrm{S} 3+\mathrm{S} 4(226$ epochs $)$ at the same altitude in the five subjects $(\mathrm{P}<0.0110) .{ }^{* *}$ Student's t-test showed that the average of the total power of the LF/HF ratio during stages S3 + S4 in a total of 226 epochs of 30 seconds at low altitude was significantly lower than that in 175 epochs of REM sleep at $122 \mathrm{~m}$ in the five subjects $(\mathrm{P}<0.011335) .{ }^{* * *}$ Student's t-test showed that the average of the total power of the LF/HF ratio during stages $\mathrm{S} 3+\mathrm{S} 4(106$ epochs $)$ at $3480 \mathrm{~m}$ was significantly lower than that during REM sleep $(113$ epochs $)$ at high altitude in the five subjects $(\mathrm{P}<0.036835)$. 
a decline in sympathovagal balance. At $122 \mathrm{~m}$ and at $3480 \mathrm{~m}$ the average values of LF:HF during REM sleep were similar to those observed during the awakening period during sleep (W).

\subsection{Total Power (TP, $\mathrm{ms}^{2}$ )}

\subsubsection{Sea Level (122 m)}

The average of the TP during the awakening period during sleep (W: $33,057 \pm 18,136)$ differed significantly from that recorded during S3 + S4 $(13,007 \pm 4621 ; \mathrm{P}<$ 0.0068). During S3 + S4 of NREM sleep (13,007 \pm 4621$)$, the average of the TP differed significantly from that observed during REM sleep $(28,480 \pm 14,192 ; \mathrm{P}<$ 0.003341) (Table 8). The TP during REM sleep was similar to the TP values recorded during $\mathrm{W}$.

\subsubsection{High Altitude ( $3480 \mathrm{~m})$}

During S3 + S4 of NREM sleep (9202 \pm 3805$)$, the average of the TP differed significantly from that observed during REM sleep $(22,838 \pm 11,600 ; \mathrm{P}<0.002613)$ in all five subjects.

\subsubsection{Sea Level (122 $\mathrm{m})$ and High Altitude (3480 $\mathrm{m})$ (Table 8)}

During $\mathrm{W}$, the average of the total power $\left(\mathrm{TP}, \mathrm{ms}^{2}\right)$ recorded at $122 \mathrm{~m}$ was longer than that recorded at $3480 \mathrm{~m}$ in $2 / 5$ subjects [(MR: $50,528 \pm 7837$ at $122 \mathrm{~m}$ vs 30,899 at $3480 \mathrm{~m} ; \mathrm{P}<0.0254)$; (DC: $17,740 \pm 23,122$ at $122 \mathrm{~m}$ vs $11,197 \pm 11,829$ at $3480 \mathrm{~m}$; P $<0.0020)$ ] (Table 8). During S1 + S2 the average of the TP at low altitude was significantly longer than that observed at $3480 \mathrm{~m}$ in $3 / 5$ subjects [(MR: 21,950 \pm 8436 at $122 \mathrm{~m}$ vs $16,258 \pm 9971$ at $3480 \mathrm{~m} ; \mathrm{P}<0.0015)$; (GM: 20,200 $\pm 11,240$ at $122 \mathrm{~m}$ vs $15,218 \pm 7421$ at $3480 \mathrm{~m}$; P < 0.0079); (DC: $7240 \pm$ 2998 at $122 \mathrm{~m}$ vs $6021 \pm 3589$ at $3480 \mathrm{~m} ; \mathrm{P}<0.00019)$ ]. During S3 + S4 the average of the TP at $122 \mathrm{~m}$ was significantly longer than that observed at $3480 \mathrm{~m}$ in $4 / 5$ subjects (CS: $13,176 \pm 3660$ at $122 \mathrm{~m}$ vs $8733 \pm 5824$ at $3480 \mathrm{~m}$; $\mathrm{P}<0.0275$ ); (MR: 17,278 \pm 4805 at $122 \mathrm{~m}$ vs $6865 \pm 720$ at $3480 \mathrm{~m} ; \mathrm{P}<0.0001$ ); (DC: $6917 \pm 3007$ at $122 \mathrm{~m}$ vs $5262 \pm 4686$ at $3480 \mathrm{~m} ; \mathrm{P}<0.0307)$ (SS: $15,005 \pm 5017$ at $122 \mathrm{~m}$ vs $10,516 \pm 9526$ at $3480 \mathrm{~m} ; \mathrm{P}<$ $0.0002)$. At $3480 \mathrm{~m}$ during the awakening period during sleep (W: $25,672 \pm 15,424$ ), the average of the TP differed significantly from that recorded during S3 + S4 $(9202 \pm 3805 ; \mathrm{P}<0.028)$. The average of the TP recorded during REM sleep at sea level was significantly shorter than that at altitude in 2/5 subjects (CS: 39,198 \pm 13,892 at $122 \mathrm{~m}$ vs $22,879 \pm 8,514$ at $3480 \mathrm{~m} ; \mathrm{P}<$ $0.0320)$; (SS: $25,442 \pm 11,874$ at $122 \mathrm{~m}$ vs $14,723 \pm 7978$ at $3480 \mathrm{~m} ; \mathrm{P}<0.0001)$.

At $122 \mathrm{~m}$ and at $3480 \mathrm{~m}$, there was a decrease in TP during deepening of NREM sleep. At $122 \mathrm{~m}$ and at 3480 $\mathrm{m}$, the average values of TP during REM sleep were similar to those observed during awakening during sleep (W).

\section{Discussion}

Fluctuations in autonomic cardiovascular regulation during exposure to high-altitude environment may increase the risk of heart attack. This study compared heart rate variability (HVR) and its components during sleep: at low altitude and after 30 - 41 hours of acclimatization at high altitude $(3480 \mathrm{~m})$ in mountain marathon runners controlled for diet, drugs, light-dark cycle and jet lag differences. At altitude, RR-intervals became significantly shorter $(\mathrm{P}<0.001)$. The significant changes in sympathetic/parasympathetic autonomic cardiovascular modulation at high altitude can protect against excessive oxygen deprivation, particularly during sleep, and thus lower the risk of heart attack. Increase in R-R intervals during wake and sleep may require longer periods of acclimatization at $3480 \mathrm{~m}$ to mitigate the effects of altitude/hypoxia on the sympathetic tone of the mountain marathon runners, thus reducing cardiovascular distress.

\section{Background}

Molecular oxygen is essential for all higher forms of life and brain cell function. During evolution, humans and other animal species developed molecular, biochemical and physiological mechanisms to optimize oxygen utilization efficacy. Humans respond to acute or chronic exposure to hypobaric-hypoxia by resetting the $\mathrm{pO}_{2}$ balance to ensure brain and heart cell function. Understanding how the body adjusts its biochemical and physiological cellular needs may help to better define the health risks associated with activities in hypobaric-hypoxia conditions and can aid in identifying appropriate therapeutic non-pharmacological and/or pharmacological treatments. Our ability to breathe and to modify breathing according to the amount of available ambient oxygen and to our body's demands (particularly those of the brain, heart and lungs) is essential for survival. Failure to breathe or an inadequate oxygen supply, especially to the brain, contributes to cardiorespiratory distress. In hypoxic conditions, distribution of cardiac output to the cardiovascular beds is subordinate to a preprogrammed priority program for preservation of the organism. In hypoxic conditions, the majority of neuronal systems of the brain increase and/or change their firing rate in order to modulate in a cyclic manner the discharge of the neurons involved in regulating the oxygen supply in mammals $[15,16,18$, 19].

Acute and chronic exposure to hypoxemia leads to all sorts of disturbances that suggest impaired excitatory neuronal functions involved in the behavioral and metabolic integration of autonomic control and arousal [15]. 
Table 8. Averages of the total power $\left(\mathrm{TP}, \mathrm{ms}^{2}\right)$ in a physiologically defined number of 30-second EEG signal epochs, according to standard criteria developed by Rechtschaffen and Kales (1968), during the waking state during sleep (W), stages $\mathbf{S 1}+$ $\mathrm{S} 2$ and $\mathrm{S3}+\mathrm{S} 4$ of NREM sleep and REM sleep at $122 \mathrm{~m}$ and after $30-41 \mathrm{~h}$ of acclimatisation at $3480 \mathrm{~m}$ in the five subjects.

\begin{tabular}{|c|c|c|c|c|c|c|c|c|c|}
\hline Stages & Subjects & \multicolumn{3}{|c|}{$122 \mathrm{~m}$} & \multicolumn{3}{|c|}{$3480 \mathrm{~m}$} & \multirow[b]{3}{*}{ Delta } & \multirow[b]{3}{*}{ P value } \\
\hline \multirow{9}{*}{ Awakening during sleep } & & Epochs & & & Epochs & & & & \\
\hline & & N. & Mean & S.D. & N. & Mean & S.D. & & \\
\hline & C.S & 7 & 33,449 & 24,257 & 35 & 25,486 & 16,753 & -7963 & n.s. \\
\hline & G.M. & 13 & 29,277 & 9809 & 12 & 28,573 & 22,336 & -704 & n.s. \\
\hline & D.C. & 140 & 17,740 & 23,122 & 157 & 11,197 & 11,829 & -6543 & 0.002 \\
\hline & S.S. & 27 & 34,293 & 25,655 & 64 & 32,203 & 20,358 & -2090 & n.s. \\
\hline & No. of epochs & 190 & & & 271 & & & & \\
\hline & & No. of subjects & Mean & $\begin{array}{c}\text { S.E.M. } \\
\text { subjects }\end{array}$ & No. of subjects & Mean & $\begin{array}{c}\text { S.E.M. } \\
\text { subjects }\end{array}$ & Delta & \\
\hline & Average & 5 & 33,057 & 18,136 & 5 & 25,672 & 15,424 & -7385 & n.s. \\
\hline \multirow[t]{8}{*}{$S 1+S 2$} & & Epochs & & & Epochs & & & & \\
\hline & & N. & Mean & S.D. & N. & Mean & S.D. & Delta & $P$ value \\
\hline & C.S & 45 & 29,292 & 16,380 & 34 & 22,533 & 13,712 & -6758 & \\
\hline & M.R. & 58 & 21,950 & 8436 & 52 & 16,258 & 9971 & -5692 & n.s. \\
\hline & G.M. & 53 & 20,200 & 11,240 & 54 & 15,218 & 7421 & -4982 & 0.0015 \\
\hline & S.S. & 200 & 25,316 & 18,423 & 237 & 29,006 & 16,917 & 3690 & 0.0001 \\
\hline & No. of epochs & 658 & & & 683 & & & & 0.0297 \\
\hline & & No. of subjects & Mean & $\begin{array}{l}\text { S.E.M. } \\
\text { subjects }\end{array}$ & No. of subjects & Mean & $\begin{array}{c}\text { S.E.M. } \\
\text { subjects }\end{array}$ & Delta & \\
\hline \multirow{10}{*}{$S 3+S 4$} & Average & 5 & 20,836 & 11,495 & 5 & 17,807 & 10,322 & -3028 & n.s \\
\hline & & Epochs & & & Epochs & & & & \\
\hline & & N. & Mean & S.D. & N. & Mean & S.D. & Delta & $P$ value \\
\hline & C.S & 16 & 13,176 & 3660 & 9 & 8733 & 5824 & -4443 & 0.0275 \\
\hline & M.R. & 11 & 17,278 & 4805 & 6 & 6865 & 720 & $-10,412$ & 0.0001 \\
\hline & G.M. & 9 & 12,659 & 6614 & 7 & 11,634 & 6801 & -1025 & n.s. \\
\hline & D.C. & 98 & 6917 & 3007 & 25 & 5262 & 4686 & -1655 & 0.0307 \\
\hline & S.S. & 92 & 15,005 & 5017 & 59 & 10,516 & 9526 & -4489 & 0.0002 \\
\hline & No. of epochs & 226 & & & 106 & & & & \\
\hline & & No. of subjects & Mean & $\begin{array}{c}\text { S.E.M. } \\
\text { subjects }\end{array}$ & No. of subjects & Mean & $\begin{array}{c}\text { S.E.M. } \\
\text { subjects }\end{array}$ & Delta & \\
\hline \multirow{8}{*}{ REM } & Average & 5 & $13,0007^{*}$ & 4621 & 5 & $9202^{* * *}$ & 3805 & -3798 & n.s. \\
\hline & M.R. & 23 & 33,035 & 14,907 & 13 & 22,879 & 8514 & $-10,156$ & 0.032 \\
\hline & G.M. & 10 & 23,552 & 6159 & 13 & 29,734 & 9673 & 6182 & n.s. \\
\hline & D.C. & 62 & 21,174 & 24,128 & 30 & 17,396 & 17,929 & -3778 & n.s. \\
\hline & S.S. & 72 & 25,442 & 11,874 & 52 & 14,723 & 7978 & 10,719 & 0.0001 \\
\hline & No. of epochs & 175 & & & 113 & & & & \\
\hline & & No. of subjects & Mean & $\begin{array}{c}\text { S.E.M. } \\
\text { subjects }\end{array}$ & No. of subjects & Mean & $\begin{array}{c}\text { S.E.M. } \\
\text { subjects }\end{array}$ & Delta & \\
\hline & Average & 5 & $28,480^{* * *}$ & 14,192 & 5 & $22,838^{* * * *}$ & 116,000 & -5642 & n.s. \\
\hline
\end{tabular}

Footnotes to Table 8: ${ }^{(1)}$ One-way ANOVA showed a significant difference in the average of the total power $(\mathrm{TP})$ between conditions $(\mathrm{DF} 7,32,39 ; \mathrm{F}=5433 ; \mathrm{P}=$ $0.0004)$. Post-hoc Fisher analysis revealed a significant difference between the average of the TP recorded at $122 \mathrm{~m}$ during waking (W) and that recorded at 122 $\mathrm{m}$ during stages $\mathrm{S} 1+\mathrm{S} 2(\mathrm{P}<0.05)$ and during stages $\mathrm{S} 3+\mathrm{S} 4(\mathrm{P}<0.05)$. Post-hoc Fisher analysis revealed a significant difference between the average of the TP recorded at $122 \mathrm{~m}$ during waking $(\mathrm{W})$ and that at $3480 \mathrm{~m}$ during stages $\mathrm{S} 1+\mathrm{S} 2(\mathrm{P}<0.05)$ and stages $\mathrm{S} 3+\mathrm{S} 4(\mathrm{P}<0.05)$. Post-hoc Fisher analysis revealed a significant difference between the average of the TP recorded at $122 \mathrm{~m}$ during waking $(\mathrm{W})$ and that at $3480 \mathrm{~m}$ during REM sleep (P $<0.05)$. Post-hoc Fisher analysis revealed a significant difference between the average of the TP recorded at $3480 \mathrm{~m}$ during stages S3 $+\mathrm{S} 4$ and that at $122 \mathrm{~m}$ during stages $\mathrm{S} 3+\mathrm{S} 4$ ( $\mathrm{P}<$ 0.05). Post-hoc Fisher analysis revealed a significant difference between the average of the TP recorded at $122 \mathrm{~m}$ during stages $\mathrm{S} 1+\mathrm{S} 2$ and that at $3480 \mathrm{~m}$ during REM sleep $(\mathrm{P}<0.05)$. Post-hoc Fisher analysis revealed a significant difference between the average of the TP recorded at $3480 \mathrm{~m}$ during stages $\mathrm{S} 1+\mathrm{S} 2$ and that at $122 \mathrm{~m}$ during REM sleep $(\mathrm{P}<0.05)$. Post-hoc Fisher analysis revealed a significant difference between the average of the TP recorded at $122 \mathrm{~m}$ during stages S3 + S4 and that at $122 \mathrm{~m}$ during REM sleep $(\mathrm{P}<0.05)$. Post-hoc Fisher revealed a significant difference between the average of the TP recorded at $3480 \mathrm{~m}$ during stages S3 $+\mathrm{S} 4$ and that at $122 \mathrm{~m}$ during REM sleep $(\mathrm{P}<0.05)$. Post-hoc Fisher analysis revealed a significant difference between the average of the TP recorded at $3480 \mathrm{~m}$ during stages S3 + S4 and that at $3480 \mathrm{~m}$ during REM sleep $(\mathrm{P}<0.05)$ in the five subjects. Post-hoc analysis with Student's t-test showed a significant difference $(\mathrm{P}<0.05)$ between the average of the total power (TP, $\left.\mathrm{ms}^{2}\right)$, in a physiologically defined number of 30 -second signal epochs, according to standard criteria developed by Rechtschaffen and Kales (1968), recorded during the waking state during sleep (W) (190 epochs) and that during stages S3 + S4 $(226$ epochs $)$ at $122 \mathrm{~m}(\mathrm{P}<0.0068)$ in the five subjects. ${ }^{* *}$ Post-hoc analysis with Student's t-test showed a significant difference $(\mathrm{P}<0.028)$ between the average of the total power (TP, $\left.\mathrm{ms}^{2}\right)$, in a physiologically defined number of 30 -second signal epochs, according to standard criteria developed by Rechtschaffen and Kales (1968), recorded during the waking state during sleep (W) (271 epochs) and that during stages S3 + S4 (106 epochs) at 3480 m in the five subjects. ${ }^{* * *}$ Post-hoc analysis with Student's t-test showed a significant difference $(\mathrm{P}<0.003341)$ between the average of the total power $\left(\mathrm{TP}, \mathrm{ms}^{2}\right)$, in a physiologically defined number of 30-second signal epochs, according to standard criteria developed by Rechtschaffen and Kales (1968), recorded during stages S3 + S4 (226 epochs) and that during REM sleep $\left(175\right.$ epochs) at $122 \mathrm{~m}$ in the five subjects. ${ }^{* * * *}$ Post-hoc analysis with Student's t-test showed a significant difference (P $<$ 0.002613 ) between the average of the total power (TP, $\left.\mathrm{ms}^{2}\right)$, in a physiologically defined number of 30 -second signal epochs, according to standard criteria developed by Rechtschaffen and Kales (1968), recorded during stages S3 + S4 (106 epochs) and that during REM sleep (113 epochs) at $3480 \mathrm{~m}$ in the five subjects. 
Research into the causes of cardiovascular mortality, experimental evidence for a predisposition to fatal arrhythmias, signs of tonic or phasic increased sympathetic activity, and reduced parasympathetic-cholinergic-vagal activity has advanced efforts for the development of quantitative markers of heart rate variability (HRV) (Task Force, [1]).

\subsection{Heart Rate Variability during Wake and Sleep}

HRV has been established as a non-invasive tool to study cardiac autonomic activity and proposed as a predictor for evaluating the increased risk of cardiac death. Interactions of changes in cardiac autonomic nervous modulation in various types of subjects are under study by the Task Force [1]. An overnight declining trend of HRV has been found to increase during sleep [14]. Otzenberger and co-workers [14] demonstrated that overnight profiles of the R-R intervals are related to changes in the sleep EEG mean frequency sign, which reflects the depth of sleep. During attentive-to-quiet waking and from the lighter to the deeper phases of sleep, HRV has been shown to be affected by vagal/sympathetic modulation and control.

\subsection{Heart Rate Variability and Mountain Marathon Runners}

Past studies showed that the high-altitude endurance performance of mountain marathoners is appreciably reduced at $5200 \mathrm{~m}$. Based on their clinical characteristics, mountain marathoners can be considered as a physiological model for studying cardiovascular alterations, of long-lasting stay and exercise at high altitude. Over the last 12 years, the time course of cardiovascular changes in the mountain marathon runners has been assessed before, during, and after the end of races at altitude. In sealevel native mountain marathoners, long-lasting training - from sea level to altitude - can lower the HR, during rest and exercise, associated with a decrease in sympathetic modulation and a rise in parasympathetic activity [20]. As in normal subjects, so too in well-trained mountain marathoners cardiovascular modifications can change continuously over a $24-\mathrm{h}$ period during acclimatization and the nocturnal sleep-wake-cycle at low and high altitudes. In mountain marathoners, just as in normal subjects, HRV alterations at altitude may include altered resting HR due to changes in the vagal and sympathetic components, besides the appearance of sinus arrhythmia during waking and periodically during nocturnal S1 + S2 NREM sleep and REM sleep breathing.

As suggested by the Task Force [1], the present study data were obtained during sleep and as such may add valuable insights for research into HRV. With this study we also wanted to determine whether 20 years of training between $122 \mathrm{~m}$ and $5200 \mathrm{~m}$ altitude could have exerted, in addition to the changes reported elsewhere [9,12], a high impact on the autonomic/cardiovascular systems of the mountain marathon runners during the nocturnal sleepwake cycle at low and at high altitudes.

Our study documents that, in mountain marathoners, the nocturnal sleep-wake cycle at $122 \mathrm{~m}$ is highly influence by autonomic parasympathetic activity and by increased autonomic parasympathetic activity during the deepening of NREM sleep. The results also show a physiological decrease in parasympathetic activity versus an increase in sympathetic activity during all phases of the nocturnal sleep-wake cycle at $3480 \mathrm{~m}$. Surprisingly, our study also documents that the nocturnal sleep-wake cycle at $3480 \mathrm{~m}$ is still characterized by an increase in autonomic parasympathetic activity during light $\mathrm{S} 1+\mathrm{S} 2$ NREM sleep. At both altitudes, the trend of the balance of parasympathetic/sympathetic activity recorded during REM sleep is similar to that recorded during the awakening state $(\mathrm{W})$.

\subsection{R-R Intervals (ms)}

\subsubsection{Sea Level (122 m)}

The averages of the R-R intervals recorded at $122 \mathrm{~m} \mathrm{did}$ not change significantly between nocturnal awakenings during sleep and sleep stages (R-R interval range, 1200 $1300 \mathrm{~ms}$ ). The average R-R interval at $122 \mathrm{~m}$, during the awaking state of sleep, was similar to that recorded during the wake state in 12 trained endurance athletes who performed a minimum of $3 \mathrm{~h}$ of aerobic activity per week [21].

\subsubsection{High Altitude $(3480 \mathrm{~m})$}

The majority of the ECG alterations in the five mountain runners, during sleep at an altitude of $3480 \mathrm{~m}$ and at a barometric pressure $\left(\mathrm{P}_{\mathrm{B}}\right)$ of $495 \mathrm{~mm} \mathrm{Hg}$, and between 30 and $41 \mathrm{~h}$ of acclimatization were: signs of sinus arrhythmia during the early stages $(\mathrm{S} 1+\mathrm{S} 2)$ of NREM sleep and during REM sleep. At $3480 \mathrm{~m}$, the average of the R-R intervals we recorded during $\mathrm{S} 1+\mathrm{S} 2$ of NREM sleep were significantly longer than those observed during the awaking period (W) during sleep. The longest average $\mathrm{R}-\mathrm{R}$ intervals were recorded during $\mathrm{S} 1+\mathrm{S} 2$ at $3480 \mathrm{~m}$. These results suggest that, at altitude, there was still a significant elevation of parasympathetic tone during S1 + S2 of slow-wave sleep versus the waking state during sleep at $3480 \mathrm{~m}$.

\subsubsection{Sea Level ( $122 \mathrm{~m})$ and High Altitude ( $3480 \mathrm{~m})$}

There was a nonpathological, significant reduction in the $\mathrm{R}-\mathrm{R}$ intervals during the awakening period during sleep (W), S1 + S2, S3 + S4 of NREM and REM sleep stages, and after $30-41 \mathrm{~h}$ of acclimatization to an altitude of 
$3480 \mathrm{~m}$, versus the averages of the R-R intervals observed during the same stages at $122 \mathrm{~m}$.

The longest average R-R intervals were recorded during the light stage of slow-wave-sleep $(\mathrm{S} 1+\mathrm{S} 2)$ at $122 \mathrm{~m}$ (suggesting high vagal activation), and the lowest average R-R intervals were recorded during the awakening period during sleep (W) at $3480 \mathrm{~m}$ (indicating an increase in noradrenergic activation). Overall, the average R-R intervals at high altitude were significantly lower than those recorded at $122 \mathrm{~m}$, with the average R-R intervals we recorded at $3480 \mathrm{~m}$, even during the awakening period (W) during sleep (935 ms). The absolute value of the R-R intervals Bernardi and co-workers [22] found in 10 sea-level native subjects at low altitude was $1002 \pm$ $45 \mathrm{~ms}$ and $809 \pm 116 \mathrm{~ms}$ in 3 high-altitude native subjects living at low altitude. In that study, the average R-R intervals in the 10 sea-level native subjects and in 3 highaltitude native subjects (living at low altitude) exposed to $4970 \mathrm{~m}$ for 3 days were $775 \pm 57$ and $749 \pm 47$, respectively. The delta of the averages of the R-R intervals that we calculated in our subjects after exposure to $3480 \mathrm{~m}$ was similar to the delta of the R-R intervals Bernardi and co-workers [22] reported. In our study, the average R-R intervals recorded at $122 \mathrm{~m}$ and $3480 \mathrm{~m}$, during all sleep stages, were also longer than those observed by Lanfranchi and co-workers [2] in 41 mountaineers, during waking, with and without AMS, and after acute exposure to approximately $4500 \mathrm{~m}$. Overall, the average R-R intervals we recorded at $122 \mathrm{~m}$ and $3480 \mathrm{~m}$ demonstrate that frequent exposure to altitudes between $122 \mathrm{~m}$ and 5500 $\mathrm{m}$, for more than 20 years, may have improved the efficacy of vagal modulation at low and high altitude during nocturnal awakening and sleep.

\subsection{Simple Linear Regression Analysis between the R-R Intervals and the $\% \mathrm{SpaO}_{2}$}

Linear regression analysis showed a significant negative correlation between the changes in the average $\% \mathrm{SpaO}_{2}$ and the changes in the average R-R intervals. The significant negative correlation between $\% \mathrm{SpaO}_{2}$ and R-R intervals may indicate that the average quantity of oxygen supplied during nocturnal sleep stages may be directly responsible for the R-R interval changes observed during nocturnal sleep, particularly at high altitude.

\subsection{Total Power of Very Low Frequency [(VLF, $\left.\left.\mathrm{ms}^{2}\right)(<0.04 \mathrm{~Hz})\right]$ Such as the Thermoregulation-Related HRV}

The thermoregulatory-related very low frequency (VLF) rhythm may be related to thermoregulatory changes or chemical and acid-base equilibrium changes, or both. Interestingly, the changes in the VLF are significantly corelated with the $\mathrm{PCO}_{2}$ changes (personal observations,
$\mathrm{DF}_{1,38,39} ; \mathrm{R}$-squared $=0.191 ;$ coefficient $=-9702.94 ; \mathrm{F}_{\text {test }}$ $=8.982 ; \mathrm{P}=0.0048 ; \mathrm{t}=1.146) ; \mathrm{tCO}_{2}$ changes (personal observations, $\mathrm{DF}_{1,38,39}$; R-squared $=0.189$; coefficient $=$ $\left.-21649.785 ; \mathrm{F}_{\text {test }}=8.871 ; \mathrm{P}=0.005 ; \mathrm{t}=2.978\right)$; and $\mathrm{HCO}_{3}^{-}$changes (personal observations, $\mathrm{DF}_{1,38,39}$; Rsquared $=0.184 ;$ coefficient $=-21682.826 ; \mathrm{F}_{\text {test }}=8.557$; $\mathrm{P}=0.0058 ; \mathrm{t}=2.925$ )

\subsubsection{Sea Level (122 m)}

At $122 \mathrm{~m}$, the average VLF decreased during S1 + S2, and significantly so during S3 $+\mathrm{S} 4$, compared with the average VLF recorded during the waking period (W). The average VLF during S3 + S4 at $122 \mathrm{~m}$ was significantly shorter than the average VLF recorded during the awakening period (W) during sleep. The average VLF during $\mathrm{S} 3+\mathrm{S} 4$ at $122 \mathrm{~m}$ was shorter than the average VLF recorded during REM sleep. At $122 \mathrm{~m}$, there was a decrease in the average VLF during NREM sleep and an increase in VLF during the desynchronized waking state. The average VLF during desynchronized REM sleep at $122 \mathrm{~m}$ was slightly shorter than the average VLF recorded during the awakening period (W) during sleep.

\subsubsection{High Altitude (3480 m)}

At $3480 \mathrm{~m}$, the average VLF decreased during S1 + S2, and significantly so during $\mathrm{S} 3+\mathrm{S} 4$, compared with the average VLF recorded during the awaking period (W) during sleep. The average VLF during S3 + S4 at $3480 \mathrm{~m}$ was significantly shorter than the average VLF recorded during the awakening period (W) during sleep. At 3480 $\mathrm{m}$, there was a decrease in the average VLF during NREM sleep and an increase during the desynchronized awaking state during sleep and REM sleep. The average VLF during REM sleep at $3480 \mathrm{~m}$ was slightly shorter than that observed during the awakening period (W) during sleep.

\subsubsection{Sea Level $(122 \mathrm{~m})$ and High Altitude $(3480 \mathrm{~m})$}

The average VLF during the awakening period (W) during sleep, S1 + S2, S3 + S4, and REM sleep at $122 \mathrm{~m}$ was longer, but not significantly so, compared with the average VLF observed at $3480 \mathrm{~m}$.

\subsection{Total Power of Low Frequency [(LF, $\left.\mathrm{ms}_{2}\right)$ (0.04 - 0.15 Hz)] Range. The LF Appears to Have a Widespread Neuronal Genesis and Is Considered as a Marker of Sympathetic Modulation or a Marker of Both Sympathetic and Vagal Modulation}

\subsubsection{Sea Level (122 m)}

Statistical analysis of our data revealed that the average of the LF during desynchronized REM sleep at $122 \mathrm{~m}$ was significantly longer than that recorded during syn- 
chronized S3 + S4 sleep. These data demonstrate an increase in parasympathetic tone during REM sleep.

\subsubsection{High Altitude (3480 m)}

In altitude there was a significant increase in sympathetic tone throughout the awakening period (W) during sleep, the $\mathrm{S} 1+\mathrm{S} 2$, and the REM sleep. The sympathetic tone decreased during the deep phase of slow wave sleep (S3 $+\mathrm{S} 4)$.

\subsubsection{Sea Level (122 $\mathrm{m})$ and High Altitude $(3480 \mathrm{~m})$}

No significant changes were found between the average $\mathrm{LF}$ recorded at $122 \mathrm{~m}$ and that recorded at $3480 \mathrm{~m}$. However, in some subjects, a significant decrease emerged between the average of LF recorded during the awakening period (W) during sleep, $\mathrm{S} 1+\mathrm{S} 2$, S3 + S4, and REM sleep at $122 \mathrm{~m}$ versus the average of LF recorded at 3480 $\mathrm{m}$.

The average LF recorded in all 5 mountain marathoners and in all 4 stages of desynchronization and synchronization at $122 \mathrm{~m}$ and at $3480 \mathrm{~m}$ (Table 3) were longer than the average LF Ako and co-workers [3] observed in 7 subjects during sleep at sea level.

We also found a decrease in the average LF during S3 $+\mathrm{S} 4$ at $122 \mathrm{~m}$ and $3480 \mathrm{~m}$ compared with the average LF recorded during $\mathrm{S} 1+\mathrm{S} 2$. The average $\mathrm{LF}$ recorded in our study during the desynchronized REM sleep state, at 122 $\mathrm{m}$ and $3480 \mathrm{~m}$, returned to similar values we recorded during the desynchronized awakening period (W) during sleep. A comparison of LF indices in the different sleep stages recorded at $122 \mathrm{~m}$ and at $3480 \mathrm{~m}$ revealed a decrease in the LF from the waking to the deep stages of sleep. The average LF during REM sleep was similar to the average LF recorded during waking. Like those of Ako and co-workers [3], our data suggest that sympathetic nervous activity decreases as sleep deepens and concomitantly increases during desynchronization of the awakening period (W) during sleep and even more so during desynchronization during REM sleep. In our study, the average LF, a marker of sympathetic modulation, during the awakening period (W) during sleep, S1 + S2, $\mathrm{S} 3+\mathrm{S} 4$, and REM sleep at $122 \mathrm{~m}$ and at $3480 \mathrm{~m}$ was lower.

\section{7. $\mathrm{LF}_{\mathrm{RR}} \mathrm{NU}$}

The aim of this study was also to verify whether autonomic variables at low altitude could predict prodromic signs of AMS when subjects were exposed to high altitude or whether subjects experienced AMS at high altitude. Autonomic cardiovascular function was also explored by measuring widespread neuronal genesis rhythm low frequency in normalized unit $\left(\mathrm{LF}_{\mathrm{RR}} \mathrm{NU}\right)$ to study sympathetic modulation.
Lanfranchi and co-workers [2] reported a substantial increase in the $\mathrm{LF}_{\mathrm{RR}} \mathrm{NU}$ component at altitude, suggesting an increase in sympathetic modulation in response to hypoxia at $4500 \mathrm{~m}$. During exposure to high altitude, besides shorter R-R intervals, we also found a relative, though not significant, increase in the $\mathrm{LF}_{\mathrm{RR}} \mathrm{NU}$ component.

We agree with Lanfranchi and co-workers [2] that this increase in the $\mathrm{LF}_{\mathrm{RR}} \mathrm{NU}$ component may reflect an increase in the sympathetic modulation of HR. During exposure to $3480 \mathrm{~m}$, R-R interval variability decreased as the LF component increased, suggesting an increase in sympathetic modulation in response to hypobaric-hypoxia. The average $\mathrm{LF}_{\mathrm{RR}} \mathrm{NU}$ Lanfranchi and co-workers [2] recorded in 24 subjects without AMS after exposure to approximately $4500 \mathrm{~m}$ during waking was similar to the average we recorded in our subjects during the awakening period (W) during sleep at $3480 \mathrm{~m}$ (73 vs 75, respectively).

$\mathrm{LF}_{\mathrm{RR}} \mathrm{NU}$ has been said to be a quantitative marker of the cardiac vigil (Vanderwalle et al. [23]) and sympathetic outflow of the autonomic nervous system. By means of spectral analysis of subjects in supine position, the Task Force [1] calculated an average $\mathrm{LF}_{\mathrm{RR}} \mathrm{NU}$ of 54, which is fairly similar to the average values in $4 / 5$ of our subjects: 47 in CS, 45 in DC, and 39 in SS in supine position during $\mathrm{S} 3+\mathrm{S} 4$ at $122 \mathrm{~m}$. Overall, the average $\mathrm{LF}_{\mathrm{RR}} \mathrm{NU}$ reported by the Task Force [1] is somewhat lower than our data (54 vs 39 - 89, respectively).

From a steady-state HRV analysis, Murrel and coworkers [24] found an average $\mathrm{LF}_{\mathrm{RR}} \mathrm{NU}$ of 77 in the standing position and premarathon conditions, an average between 72 and 92 immediately after a marathon, and an average of 73 in the standing position at $48 \mathrm{~h}$ postmarathon. These data appear similar to the data we recorded at $122 \mathrm{~m}$ and $3480 \mathrm{~m}$ during the awakening, S1 + S2, S3 + $\mathrm{S} 4$, and REM stages of sleep.

Specifically, at $122 \mathrm{~m}$ there was a decrease in $\mathrm{LF}_{\mathrm{RR}} \mathrm{NU}$ as sleep depth increased; during the desynchronized phase of sleep (the awakening state), the $\mathrm{LF}_{\mathrm{RR}} \mathrm{NU}$ reached the values observed during REM sleep. At $3480 \mathrm{~m}$ there was a decrease in $\mathrm{LF}_{\mathrm{RR}} \mathrm{NU}$ as sleep deepened; during the desynchronized phase of sleep (the awakening state) the $\mathrm{LF}_{\mathrm{RR}} \mathrm{NU}$ reached the values recorded during the REM phases at $3480 \mathrm{~m}$.

\subsection{High Frequency}

Efferent vagal activity is a major contributor to the high frequency (HF) component (Task Force, [1]) which primarily reflects respiration-driven vigil modulation of the sinus rhythm. Other factors such as voluntary controlled respiration, cold stimulation of the face or rotational motor stimuli (see above) can occur physiologically during 
sleeping and might confound results. Spectral analysis of stationary supine subjects revealed an average normal HF close to $975 \mathrm{~ms}^{2}$ (Task Force, [1]). Saito and co-workers [25] reported an average $\mathrm{HF}$ of $780 \pm 211 \mathrm{~ms}^{2}$ in $21 \mathrm{sub}-$ jects during waking at low altitude and an average $\mathrm{HF}$ between $61 \pm 44$ and $112 \pm 128 \mathrm{~ms}^{2}$ after exposure for 4 $6 \mathrm{~h}$ at $\mathrm{P}_{\mathrm{B}} 495 \mathrm{~mm} \mathrm{Hg}$. Lanfranchi and co-workers [2] reported an average HF between $102 \pm 37$ and $157 \pm 43$ $\mathrm{ms}^{2}$ in subjects exposed to approximately $4500 \mathrm{~m}$, or between $135 \pm 30$ and $64 \pm 4 \mathrm{~ms}^{2}$ in those with no signs of AMS. Briefly, in the subjects without AMS there was a non significant increase in the HF component. At low altitude, the average HF in our five mountain marathon runners increased as sleep deepened and decreased during REM sleep to levels similar to those observed in the waking state. The average $\mathrm{HF}$ at altitude was $1572 \mathrm{~ms}^{2}$ during the awakening state, $1610 \mathrm{~ms}^{2}$ during $\mathrm{S} 1+\mathrm{S} 2$, $1480 \mathrm{~ms}^{2}$ during S3 + S4, and $1159 \mathrm{~ms}^{2}$ during REM sleep. The average HF decreased during the sleep stages. Surprisingly, the average HF of $1159 \mathrm{~ms}^{2}$ during REM sleep at high altitude was lower than the average observed during the desynchronized state during waking.

As reported by the Task Force [1], we also found the HF vigil component of the power spectrum to be augmented during NREM sleep at low altitude.

\section{9. $\mathrm{HF}_{\mathrm{RR}} \mathrm{NU}$}

The average of total power expressed in high frequency ${ }_{R R}$ normalized units $\left(\mathrm{HF}_{\mathrm{RR}} \mathrm{NU}\right)$ is considered a marker of vagal modulation of the autonomic system. The values that we found at low altitude during the awakening period (W) during sleep, during $\mathrm{S} 2+\mathrm{S} 3$ and $\mathrm{S} 3+\mathrm{S} 4$, and during REM sleep were similar to those Murrell and coworkers [24] recorded at premarathon, postmarathon, and $48 \mathrm{~h}$ postmarathon assessment under controlled normal breathing and standing conditions. Our $\mathrm{HF}_{\mathrm{RR}} \mathrm{NU}$ data recorded during the awakening period (W) during sleep at 122 and were similar to those they reported during REM sleep (23.47 versus 22.64, respectively). In their evaluation of $\mathrm{LF}_{\mathrm{RR}} \mathrm{NU}$, the average HF (controlled breathing) was 58.45 during the premarathon stage, 45 during, and 53 at $48 \mathrm{~h}$ postmarathon The average $\mathrm{HF}_{\mathrm{RR}} \mathrm{NU}$ decreased immediately after the race and at $48 \mathrm{~h}$ postmarathon. All these values are very close to the average $\mathrm{LF}_{\mathrm{RR}} \mathrm{NU}$ we recorded in the subjects during $\mathrm{S} 3+\mathrm{S} 4$ sleep at low altitude.

Of note is that $\mathrm{HF}_{\mathrm{RR}} \mathrm{NU}$ at low and at high altitudes increases at sleep onset and peaks during the deep stage of sleep $(\mathrm{S} 3+\mathrm{S} 4)$ at altitude (56.91). After exposure to $3480 \mathrm{~m}$ at a $\mathrm{P}_{\mathrm{B}}$ of $495 \mathrm{~mm} \mathrm{Hg}$ for $30-41 \mathrm{~h}$ there was a non significant reduction in $\mathrm{HF}_{\mathrm{RR}} \mathrm{NU}$ across all sleep stages. The average $\mathrm{HF}_{\mathrm{RR}} \mathrm{NU}$ during the awakening period (W) during sleep at $3480 \mathrm{~m}$ was lower but still simi- lar to that at $122 \mathrm{~m}$. These values were similar, though lower, than those Murrell and co-workers [24] recorded immediately and at $48 \mathrm{~h}$ post-marathon at altitude.

Our $\mathrm{HF}_{\mathrm{RR}} \mathrm{NU}$ data recorded during sleep at $122 \mathrm{~m}$ and $3480 \mathrm{~m}$ were also similar to those Lanfranchi and coworkers [2] reported in subjects without AMS and those with AMS (16 and 31, respectively) during the supposed diurnal state and after exposure to $4500 \mathrm{~m}$.

Compared with the $\mathrm{HF}_{\mathrm{RR}} \mathrm{NU}$ reported by the Task Force [1], our data recorded during the awakening state, $\mathrm{S} 1+\mathrm{S} 2$ and $\mathrm{S} 3+\mathrm{S} 4$ and REM sleep at sea level and at $3480 \mathrm{~m}$ were 21.31 and 31.11 respectively.

\subsection{LF:HF Ratio}

Exercise and training at low and high altitudes may have modified autonomic nervous system balance and thus the LF:HF ratio. The LF:HF ratio is considered by some investigators as the mirror of sympathovagal balance or a reflection of sympathetic modulation (Ako et al. [3]). In agreement with Ako and co-workers [3], we observed, significantly at low altitude, but indeed also at high altitude, a significant decrease in the LF:HF component as sleep deepened. In agreement with Ako and co-workers [3], we also observed that the sympathetic nervous system is activated during the two desynchronisation phases of REM sleep and deactivated during NREM sleep at low and high altitude.

In detail, we analyzed the dynamics of nocturnal fluctuations of autonomic nerve activities in sleep stages classified by Rechtschaffen and Kales's criteria. These criteria have not yet been investigated in association with HRV indices, particularly during hypoxic conditions. Ako and co-workers [3] found an increase in the LF:HF ratio $(2.51 \pm 0.17)$ during $R E M$ sleep and a significant linear decrease during NREM sleep $\left(\mathrm{S}_{1} 2.30 \pm 0.29 ; \mathrm{S}_{2}\right.$ $\left.1.85 \pm 0.09 ; \mathrm{S}_{3} 0.78 \pm 0.06 ; \mathrm{S}_{4} 2.51 \pm 0.17\right)$. Like Ako and co-workers [3], we noted a reduction in the LF:HF ratio at $122 \mathrm{~m}$ and at $3480 \mathrm{~m}$ during NREM sleep (S1 + $\mathrm{S} 2_{122}$ m 3.1187; S1 + S2 3480 m 5.1242; S3 + S4 122 m 1.6733; $\mathrm{S} 3+\mathrm{S} 43480 \mathrm{~m}$ 3.2109) and an increase during REM sleep $\left(\mathrm{REM}_{122 \mathrm{~m}}\right.$ 4.4739; $\mathrm{REM}_{3480 \mathrm{~m}}$ 6.9132) to the level found during the awaking period $(\mathrm{W})$ during sleep $\left(\mathrm{W}_{122 \mathrm{~m}}\right.$ 4.6446 and $\mathrm{W}_{3480 \mathrm{~m}} 6.0036$ ). We also found that the average LF:HF ratio during S3 + S4 of NREM sleep at 122 $\mathrm{m}(\mathrm{LF}: \mathrm{HF}=1.6733)$ was similar to that reported by the Task Force [1] (LF:HF 1.5 - 2.0) in the spectral analysis of stationary supine 5-minute recordings. In our study, the average LF:HF ratio at $122 \mathrm{~m}$ and $3480 \mathrm{~m}$ during the awaking period (W) during sleep ( $\mathrm{W}_{122 \mathrm{~m}} 4.6446$ and $\mathrm{W}_{3480 \mathrm{~m}} 6.0036$, respectively) was lower yet similar to the average LF:HF ratio Lanfranchi and co-workers [2] found during the waking state at $4500 \mathrm{~m}$ in mountaineers with and without AMS $(3.4 \pm 1.3$ and $8.3 \pm 14$, respectively). 
Saito and co-workers [25] found an average LF:HF ratio of $2.6 \pm 0.8$ at $P_{B} 760 \mathrm{~mm} \mathrm{Hg}$ at sea level during the relaxed waking state. This was similar to the value we found (1.6733) during S3 $+\mathrm{S} 4$ at $122 \mathrm{~m}$. They reported an average LF:HF ratio of $3.5 \pm 2.3$ at $3456 \mathrm{~m}$ and at a $\mathrm{P}_{\mathrm{B}}$ of $495 \mathrm{~mm} \mathrm{Hg}$ which was similar to the average of 3.2109 that we recorded during S3 $+\mathrm{S} 4$ at $3480 \mathrm{~m}$. The average LF:HF ratio that we found in all five mountain runners during S3 + S4 $(1.6733 \pm 1.0847)$ at $122 \mathrm{~m}$ was similar to that reported by the Task Force [1]. In some of the mountain marathon runners, at low altitude, at $122 \mathrm{~m}$, and after $30-41 \mathrm{~h}$ of acclimatization at $3480 \mathrm{~m}$ during the different stages of desynchronized and synchronized sleep, the average LF:HF ratio reached the normal values reported by the Task Force [1] (between 1.5 and 2.0). The LF:HF ratio value of 2 , which is considered normal by the Task Force [1], was recorded at $122 \mathrm{~m}$ in: $1 / 5$ subjects (SS) during the awakening period (W) of sleep; $3 / 5$ subjects (CS, DC, SS) during S1 + S2; and $5 / 5$ subjects during S3 + S4; $2 / 5$ subjects (CS, SS) during the REM sleep stage. A LF:HF ratio value of 2 was reached after $30-41 \mathrm{~h}$ of acclimatization at $3480 \mathrm{~m}$ by: $1 / 5$ subjects (GM) during the awakening period (W) of sleep; $1 / 5$ subjects (CS) during $\mathrm{S} 1+\mathrm{S} 2$; and 2/5 subjects $(\mathrm{CS}, \mathrm{GM})$ during $\mathrm{S} 3+\mathrm{S} 4$. No changes were noted between the average LF:HF ratio recorded in all five mountain runners at $122 \mathrm{~m}$ and after $30-41 \mathrm{~h}$ of acclimatization at $3480 \mathrm{~m}$ and during all four stages of sleep: awakening period (W) during sleep; S1 + S2; S3 + S4; and REM sleep. These results suggest highly controlled regulation of sympathovagal balance on exposure to moderate hypoxia conditions. As reported in Table 7, several mountain marathon runners showed very high control of sympathovagal balance: their LF:HF ratio was similar to that reported by the Task Force [1] or did not differ between $122 \mathrm{~m}$ and $3480 \mathrm{~m}$, after $30-41 \mathrm{~h}$ of acclimatization, during the awakening period $(\mathrm{W})$ during sleep, during $\mathrm{S} 1+\mathrm{S} 2$; during S3 + S4, or during the REM sleep. Cornolo and co-workers [20] reported an average LF:HF ratio of $\sim 6.0$ in trained high-altitude native subjects $6-8 \mathrm{~h}$ after the end of a marathon performed between 4100 and $4400 \mathrm{~m}$. This was similar to the average LF:HF ratio that we recorded at $3480 \mathrm{~m}$ during the desynchronized state of sleep, specifically, during the awakening period (W) during sleep $(6.0036 \pm 5.0276)$ and during the REM sleep at the same altitude $(6.9132 \pm 3.6806)$.

\subsection{Total Power}

We observed significant parallel changes in TP recorded at low $\left(\mathrm{P}_{\mathrm{B}}\right.$ about $\left.740 \mathrm{~mm} \mathrm{Hg}\right)$ and high $\left(\mathrm{P}_{\mathrm{B}} 495 \mathrm{~mm} \mathrm{Hg}\right)$ altitude between the awakening period (W) during sleep and $\mathrm{S} 3+\mathrm{S} 4$ of sleep. We also found significant parallel changes in the TP recorded during REM sleep and the average of TP recorded during S3 + S4 at 122 and 3480 $\mathrm{m}$. These changes may reflect changes in cardiac, respiratory and sympathovagal balance. In general, in individual mountain marathon runners we found a decrease in the total power at altitude. The components of HRV are thought to be influenced by both neuronal and humoral factors (Task Force, [1]). Saito and co-workers [25] reported that humoral control of the autonomic nervous system plays an important role in the survival of victims under hypoxic conditions at high altitude.

\section{Functional Significance}

Physical training at low and high altitudes may have induced marked autonomic adaptations in the mountain marathon runners over the course of their years of training. The resting heart rate was lower at sea level because parasympathetic modulation predominates over higher sympathetic control at high altitude. By constantly maintaining their training levels at low and high altitudes for more than 20 years, the mountain runners may have shifted their cardiovascular autonomic control toward a greater parasympathetic modulation, particularly at sea level. Rest and training under hypoxia conditions may have balanced the prevalence of parasympathetic modulation, as well as improved control of phasic sympathetic responses.

These well-trained runners seem to be exceptionally adapted to the high altitude environment [4-13]. Strenuous exercise is known to induce profound cardiovascular modifications, but with a caveat for non-professional marathoners.

We agree with Lanfranchi et al. [2], that HRV analysis has proved to be essential for investigating the mountain sickness, the balance of the sympathetic and parasympathetic function of the autonomic nervous system at low and high altitude in mountain marathon runners. HRV analysis could also be very useful for evaluating decreases in parasympathetic and increases in sympathetic tone of the autonomic nervous system during acclimatization at altitude of mountain marathon runners who generally have a tonic prevalence of parasympathetic tone at low altitude.

$\mathrm{R}-\mathrm{R}$ interval variability was observed in the mountain marathon runners during sleep at $122 \mathrm{~m}$ (i.e., a controlled increase in parasympathetic tone during NREM sleep and an increased sympathetic tone during the awakening period (W) during sleep and during REM sleep). At high altitude, the RR-intervals we observed were similar to those Sacknoff and co-workers [21] reported in athletes and controls. Moreover, the major ECG alterations evident during sleep, at an altitude of $3480 \mathrm{~m}$, at a $\mathrm{P}_{\mathrm{B}}$ of 495 $\mathrm{mm} \mathrm{Hg}$, and after 30 - 41 hours of acclimatization, were an increase in HR, together with signs of sinus arrhyth- 
mia during periodic breathing in $\mathrm{S} 1+\mathrm{S} 2$ of NREM sleep and in REM sleep.

This study did not find abnormal reductions in the R-R interval during the awakening period $(\mathrm{W})$ during sleep, $\mathrm{S} 1+\mathrm{S} 2, \mathrm{~S} 3+\mathrm{S} 4$ and REM sleep, between 30 and $41 \mathrm{~h}$ of acclimatization at $3480 \mathrm{~m}$ in these well-trained mountain marathon runners.

The HRV data observed at altitude suggest that the runners possess an intrinsic high parasympathetic tone that at high altitude promptly compensates the physiological increase in sympathetic tone due to a periodic, significant decrease in peripheral oxygen saturation during sleep.

Not in group average but in several individual runners we found a significant reduction in the LF component at high altitude which may be due to the rhythmic increase of sympathetic discharge of the central brain stem center.

In comparison to the average calculated at low altitude, we also found a significant decrease in the average of the power of HF during S3 + S4 of NREM sleep at $3480 \mathrm{~m}$. This significant reduction probably indicates a decrease in the vagal parasympathetic components of the brainstem generator.

The study demonstrates that cardiovascular modifications during sleep and after $30-41 \mathrm{~h}$ of acclimatization at high altitude can occur even in mountain marathoners who have benefited from 20 years of training at low and high altitude. Physicians should therefore take the results of HRV analysis into account to improve the training and performance, particularly at altitude.

\section{Acknowledgements}

Thanks are due to K. Britsch for reading the manuscript. We thank the FILA Sky Marathon for economical support from 1998 up to 2003.

\section{REFERENCES}

[1] Task Force of the European Society of Cardiology and North America Society of Pacing Electrophysiology, "Heart Rate Variability, Standard of Measurement, Physiological Interpretation and Clinical Use," European Heart Journal, Vol. 17, 1996, pp. 354-381. doi:10.1093/oxfordjournals.eurheartj.a014868

[2] P. A. Lanfranchi, R. Colombo, G. Cremona, P. Baderna, L. Spagnolati, G. Mazzuero, P. Wagner, L. Perini, H. Wagner, C. Cavallaro and P. Giannuzzi, "Autonomic Cardiovascular Regulation in Subjects with Acute Mountain Sickness," American Physiology Heart Circulation Physiology, Vol. 289, No. 6, 2005, pp. H2364-H2372. doi:10.1152/ajpheart.00004.2005

[3] M. Ako, K. Tokuhiro, S. Uchida, S. Miyazaky, K. Nishihara, J. Mukai, K. Hirao J. Ako and Y. Okubo, "Correlation between Electrophysiography and Heart Rate Variability during Sleep," Psychiatry and Clinical Neurosci- ence, Vol. 57, No. 1, 2003, pp. 59-65. doi:10.1046/j.1440-1819.2003.01080.x

[4] G. Banfi, M. Marinelli, G. S. Roi, A. Colombini, M. Pontillo, M. Giacometti and S. Wade, "Growth Hormone and Insulin-Like Growth Factor I in Athletes Performing a Marathon at $4000 \mathrm{~m}$ of Altitude," Growth Regulation, Vol. 4, 1994, pp. 82-86.

[5] M. Marinelli, G. S. Roi, M. Giacometti, P. Bonini and G. Banfi, "Cortisol, Testosterone and Free Testosterone in Athletes Performing a Marathon at $4000 \mathrm{~m}$ of Altitude," Hormon Research, Vol. 41, No. 5-6, 1994, pp. 225-229. doi:10.1159/000183929

[6] G. Banfi, M. Marinelli, G. S. Roi and M. Giacometti, "Platelet Indices in Athletes Performing a Race in Altitude Environment," Journal of Clinical Laboratory Analysis, Vol. 9, No. 1, 1995, pp. 34-36. doi:10.1002/jcla.1860090106

[7] G. Banfi, M. Marinelli, P. Bonini, I. Gritti and G. S. Roi, "Pepsinogens and Gastrointestinal Symptoms in Mountain Marathon Runners," International Journal Sports Medicine, Vol. 17, No. 8, 1996, pp. 554-558. doi:10.1055/s-2007-972894

[8] G. Banfi, M. Pontillo, M. Marinelli, A. Dolci and G. S. Roi, "Thyrotropin and Free Thyroid Hormones in Athletes during and after Ultra Endurance Sport Performances," Journal Clinical of Ligand Assay, Vol. 21, No. 3, 1998, pp. 331-334.

[9] G. S. Roi, M. Giacometti and S. P. von Duvillard, "Marathons in Altitude," Medicine \& Science in Sports \& Exercise, Vol. 31, No. 5, 1999, pp. 723-728. doi:10.1097/00005768-199905000-00016

[10] G. Banfi and A. Dolci, "Preanalytical Phase of Sport Biochemistry and Haematology," The Journal of Sports Medicine and Physical Fitness, Vol. 43, No. 2, 2003, pp. 223-230.

[11] G. Pelamatti, M. Pascotto and C. Semenza, "Verbal Free Recall in High Altitude: Proper Names vs Common Names," Cortex, Vol. 39, No. 1, 2003, pp. 97-103. doi:10.1016/S0010-9452(08)70077-7

[12] G. Fragasso, A. Palloshi, S. Roi, E. Rossetti, G. Monaco, A. Dolci, A. Margonato and S. Chierchia, "Transient Left Ventricular Diastolic Dysfunction Following Strenuous Exercise," Sport Science Health, Vol. 1, No. 1, 2004, pp. 31-35. doi:10.1007/s11332-004-0007-7

[13] I. Gritti, M. Martignoni, R. Calcaterra and G. S. Roi, "Electroencephalographic Changes after a Marathon at $4300 \mathrm{~m}$ of Altitude," Journal of Behavioral and Brain Science, Vol. 2, No. 3, 2012, pp. 380-386. doi:10.4236/jbbs.2012.23043

[14] H. Otzenberger, C. Simon, C. Gronfier and G. Brandenberger, "Temporal Relationship between Dynamic Heart Rate Variability and Electroencephalographic Activity during Sleep in Man," Neuroscience Letters, Vol. 229, No. 3, 1997, pp. 173-176. doi:10.1016/S0304-3940(97)00448-5

[15] J. H. Coote, "Medicine and Mechanisms in Altitude Sickness. Recommendations," Sports Medicine, Vol. 20, No. 3, 1995, pp. 148-159. 


$$
\text { doi:10.2165/00007256-199520030-00003 }
$$

[16] M. A. Conney, R. W. van Arts, L. A. A. Kollée, J. C. W. Hopman, G. B. A. Stoelinga, P. Herman and H. P. van Geijn, "Heart Rate Variability," Annals of Internal Medicine, Vol. 118, No. 6, 1993, pp. 436-447.

[17] A. Rechtschaffen and A. Kales, "A Manual of Standardized Terminology, Techniques and Scoring System for Sleep Stages of Human Subjects," BIS/BRI UCLA, Los Angeles, 1968.

[18] F. R. Calaresu, A. A. Faiers and G. J. Mogenson, "Central Neuronal Regulation of the Heart and Blood Vessels in Mammals," Progress Neurobiology, Vol. 5, No. 1, 1975, pp. 1-35. doi:10.1016/0301-0082(75)90006-4

[19] H. Scholz, "Adaptational Responses to Hypoxia," American Journal of Physiology and Regulatory Integrative Comparative Physiology, Vol. 282, No. 6, 2002, pp. R1541-R1543.

[20] J. Cornolo, J. V. Brugniaux, J. L. Marcarlupu, C. Privat, F. Leon-Velarde and J. P. Richalet, "Autonomic Adaptations in Andean-Trained Participants to $4220 \mathrm{~m}$ Altitude. Marathon," Medicine and Science in Sports and Exercise, Vol. 37, No. 12, 2005, pp. 2148-2153. doi:10.1249/01.mss.0000179901.19280.85

[21] D. M. Sacknoff, G. W. Gleim, N. Stachenfeld and N. L. Complan, "Effect of Athletic Training on Heart Variabil- ity," American Heart Journal, Vol. 127, No. 5, 1994, pp. 1275-1278. doi:10.1016/0002-8703(94)90046-9

[22] L. Bernardi, C. Passino, G. Spadaccini, A. Calciati, R. Robergs, R. Green, E. Martignoni, I. Anand and O. Appenzeller, "Cardiovascular Autonomic Modulation and Activity of Carotid Baroreceptors at Altitude," Clinical Science, Vol. 95, 1998, pp. 565-573. doi:10.1042/CS19980046

[23] G. Vandewalle, B. Middleton, S. W. R. Rajaratnam, B. M. Stone, B. Thorleifsdottir, J. Aredent and D. J. Dijk, "Robust Circadian Rhythm in Heart Rate and Its Variability: Influence of Melatonin and Photoperiod," Journal of Sleep Research, Vol. 16, No. 2, 2007, pp. 148-150. doi:10.1111/j.1365-2869.2007.00581.x

[24] C. Murrell, L. Wilson, J. D. Cotter, S. Lucas, S. Ogoh, G. Keith and N. Ainslie, "Alteration in Autonomic Function and Cerebral Hemodynamics to Orthostatic Challenge Following a Mountain Marathon," Journal Applied Physiology, Vol. 103, No. 1, 2007, pp. 88-96. doi:10.1152/japplphysiol.01396.2006

[25] S. Saito, K. Tanobe, M. Yamada and F. Nishihara, "Relationship between Arterial Oxygen Saturation and Heart Rate Variability at High Altitudes," American Journal of Emergency Medicine, Vol. 23, No. 1, 2005, pp. 8-12. doi:10.1016/j.ajem.2004.09.023 